\title{
Measurement Engineering to Design a Truncated Ground Plane Compact Circular Ring Monopole Patch Antenna for Ultra Wideband Applications
}

syed zeeshan Ali ( $\square$ zeeshan2058@yahoo.com )

Iqra university https://orcid.org/0000-0002-7122-4824

Ikrame E Khuda

Iqra University

Kamran Raza

Iqra University

Mansoor Ebrahim

Iqra University

\section{Research Article}

Keywords: Circular ring patch antenna, bandwidth, scattering parameters, parameter optimization

Posted Date: March 23rd, 2021

DOI: https://doi.org/10.21203/rs.3.rs-207953/v1

License: (a) (i) This work is licensed under a Creative Commons Attribution 4.0 International License. Read Full License

Version of Record: A version of this preprint was published at Wireless Personal Communications on November 30th, 2021. See the published version at https://doi.org/10.1007/s11277-021-09408-w. 


\title{
Measurement Engineering to Design a Truncated Ground Plane Compact Circular Ring Monopole Patch Antenna for Ultra Wideband Applications
}

\author{
Syed Zeeshan $\mathrm{Ali}^{1}$, Ikram E Khuda ${ }^{1},{\text { Kamran } \text { Raza }^{2} \text { and Mansoor Ebrahim }}^{3}$ \\ (1) Faculty of Engineering Sciences and Technology (FEST), \\ Iqra University Defense View, Karachi, Pakistan \\ (2) Faculty of Engineering Sciences and Technology (FEST), \\ Iqra University Defense View, Karachi, Pakistan \\ (3) Faculty of Engineering Sciences and Technology (FEST), \\ Iqra University Defense View, Karachi, Pakistan
}

\begin{abstract}
In this paper, using in-depth simulations and measurements, a simple and compact design is engineered for making a circular ring microstrip patch antenna radiating element which is suitable for different ultra wide band(UWB) applications. This design approach is different because it has not utilized the usual method of using a set of electromagnetic equations and calculations to make the radiating antenna. Measurements and simulations were performed on Microwave CST. Using this measurement engineering approach, novelty of proposed antenna structure is obtained by making the required changes in the ground plane. The measurements showed that truncating the ground plane by a square shape structure of $2.5 \mathrm{~mm}$ by $2.5 \mathrm{~mm}$ size at the feed point was practically significant to provide an impedance bandwidth $\left(S_{11}<-10 \mathrm{~dB}\right)$ ranging from $2.75 \mathrm{GHz}$ to $32.035 \mathrm{GHz}$ with a VSWR which is less than 2. For this entire bandwidth the directivity has shown a variation from $0.8 \mathrm{dBi}$ to $7.9 \mathrm{dBi}$. The compact size $(33 \mathrm{~mm} \times 28 \mathrm{~mm} \times 1.57 \mathrm{~mm})$, low design complexity, very high bandwidth, good directivity and satisfying VSWR has made this antenna unique among all previously presented UWB antennas.
\end{abstract}

Keywords Circular ring patch antenna, bandwidth, scattering parameters, parameter optimization

Corresponding author:

Syed Zeeshan Ali

Faculty of Engineering Sciences and Technology, Iqra University,

Iqra University, Main campus, Defence View, Shaheed-e-Millat Road (Ext.)

Karachi-75500, Pakistan

Cell: (+92)3332058737

E-mail: zeeshan2058@yahoo.com 


\section{Introduction}

Ultra-wideband (UWB) is a radio technology that has the advantages of using very low power spectral density (PSD) with fractional bandwidth $\geq 0.2-0.25$ or a bandwidth of at least $500 \mathrm{MHz}$. This range is usable for high bandwidth applications in engineering, medical sciences and other areas of science[1-5]. Designing a UWB communication system, entails state-of-the-art design of transmitters, receivers and radiating elements, i.e. antennas. In this paper the focus is the design of a contemporary UWB antenna with desired characteristics low volume and size.

Antennas are the radiating elements with the purpose of sending and receiving signals to and from wireless channel. In addition to many other features, speed of transmission and reception process carries a challenging research interest for a high speed communication system. Of the many factors, the high speed communication needs a high bandwidth to cover mobile and other wireless facilities. With this need of broad bandwidth, UWB antennas with low profile are the best resource for high speed communications.

In designing a UWB antenna it is important to consider the design principles, procedures and final antenna characteristics. Hence there should be no ambiguity in them. Because of their inherent advantages, the most popular of UWB antennas are microstrip patch antennas [68].Microstrip Antenna (MSA) has a three layer structure namely radiating patch, ground plane and substrate (dielectric). The substrate lies between patch and ground plane. Literature study showed thatmicrostrip antenna's type, shape, design analytics, and feeding procedures are the commonly accepted methods to improve the antenna's characteristics and performances[9-15]. These attributes help to improve the antenna parameters including return loss, gain, directivity, and bandwidth. The design process involves that the antenna designer first determines any of these parameter(s) as the required output then tries to optimize their antenna design accordingly.

Most importantly in the design of the UWB antenna, the working bandwidth should be considered according to the Federal Communications Commission (FCC). The UWB standard used in USA and Canada is unlicensed band of approximately $7.5 \mathrm{GHz}$ ranging from3.1 to 10.6 GHz. In addition, FCC has also limited the emissions for the maximum power-efficiency which is $-41.3 \mathrm{dBm} / \mathrm{MHz}[16,17]$.

A conventional microstrip patch antenna has the intrinsic properties of narrow impedance bandwidth which means that the antenna will show resonance on a single (ideally) or to a narrow band of frequencies (in practical). Several techniques have been used to enhance the impedance bandwidth of the microstrip patch antenna. Some of the commonly stated techniques in the literature study included an insertion of a slot in a patch in the form of square, ring or U-shaped slot [18-22],truncating the ground plane and designing aperture coupled patch antennas[23, 24], using integrated band pass filter [25], making use of optimally designed impedance matching network. In all these configurations, parts of the system that a designer has to model in finding antenna radiation are the surfaces of the metals, having surface charge density, which radiate electromagnetic fields. A low Q factor or alternatively high bandwidth antennahas also been achieved by increasing the thickness of the dielectric substrate [26], thus making more room for radiated energy than stored energy. However, high bandwidth antenna has a lower gain value. But by using an array configuration for the elements, the problem of lower gain and lower power handling capacity can be overcome. 
In this research, we have proposed the antenna design and its measurement engineering ofahighbandwidthUWBantenna along with a moderate structure size and good directivity bandwidth.

\section{Background / Motivation from previous Work}

In the beginning the parametric values were achieved after the theoretical and numerical analysis of various types of Microstrip Antennas (MSA's). In rectangular patch we have two parameters (Length and Width) for changing their different modes. Similarly in our design, the patch is circular ring type also have two parameters (outer radius $\mathrm{R}$ and inner radius $\mathrm{r}$ ) by which we can change their modes. So we put all the values of our proposed antenna in well known equations of rectangular patch antenna to find the length and width. Here we supposed that the value of width and length is equal to the outer radius (R) and inner radius ( $r$ ) respectively of the proposed antenna which is circular ring type. The width of rectangular patch can be found as:

$$
\mathrm{W}=\frac{\mathrm{c}}{2 \mathrm{f}_{0} \sqrt{\frac{\varepsilon_{\mathrm{r}}+1}{2}}}
$$

Here $\mathrm{c}$ is the velocity of light and is equal to $3 \times 10^{8} \mathrm{~m} / \mathrm{s}$.

$\mathrm{f}_{0}$ is the resonance frequency and is equal to $10 \mathrm{GHz}$.

and $\varepsilon_{r}$ is the relative permittivity of FR-4 which is used for substrate material, its value is 4.3. Substituting the values in eq. (1) give us,

$$
\begin{gathered}
\mathrm{w}=\frac{3 \times 10^{8}}{2 \times 10^{10} \sqrt{\frac{4.9+1}{2}}} \\
\mathrm{w}=8.89 \mathrm{~mm}
\end{gathered}
$$

Here we have supposed that the value of width in eq (2) will be equal to outer radius $(R)$ of our proposed antenna

$$
\mathrm{R}=\mathrm{w}=8.89 \mathrm{~mm}
$$

Similarly to find actual length (L) the following equations were used,

$$
\varepsilon_{e f f}=\frac{\varepsilon_{r}+1}{2}+\frac{\varepsilon_{r}-1}{2}\left(1+12 \frac{\mathrm{h}}{2}\right)^{-\frac{1}{2}}
$$

Here $\mathrm{h}$ is the height of substrate and is equal to $1.57 \mathrm{~mm}$ and $\varepsilon_{e f f}$ is the effective permittivity.

$$
\mathrm{L}_{\mathrm{eff}}=\frac{\mathrm{c}}{2 \mathrm{f}_{0} \sqrt{\varepsilon_{\text {eff }}}}
$$

Here $\mathrm{L}_{\text {eff }}$ is the effective length of rectangular patch 


$$
\Delta \mathrm{L}=0.412 \mathrm{~h} \frac{\left(\varepsilon_{e f f}+0.3\right)\left(\frac{\mathrm{w}}{\mathrm{h}}+0.264\right)}{\left(\varepsilon_{e f f}-0.258\right)\left(\frac{\mathrm{w}}{\mathrm{h}}+0.8\right)}
$$

Here $\Delta \mathrm{L}$ is the change in length of rectangular patch

$$
\mathrm{L}=\mathrm{L}_{\mathrm{eff}}-2 \Delta \mathrm{L}
$$

Finally $\mathrm{L}$ is the actual length of rectangular patch

After solving the above equations (4), (5), (6) and (7), $\mathrm{L}$ is found as,

$$
\mathrm{L}=6.26 \mathrm{~mm}
$$

We have supposed that this value of $\mathrm{L}$ in eq. (8) is equal to the inner radius $(r)$ of our proposed antenna

$$
\mathrm{r}=\mathrm{L}=6.26 \mathrm{~mm}
$$

With the help of eq (3) and eq (9) we also calculated the length and width of ground plane and truncation was performed just by rectangle shape in a simple way that one side was made twice to the other side. After getting all initial parametric values, we simulated the antenna and found the bandwidth $0.8512 \mathrm{GHz}$ with reflection coefficient $\mathrm{S}_{11}<-10 \mathrm{~dB}$. The simulation is shown in Fig 1

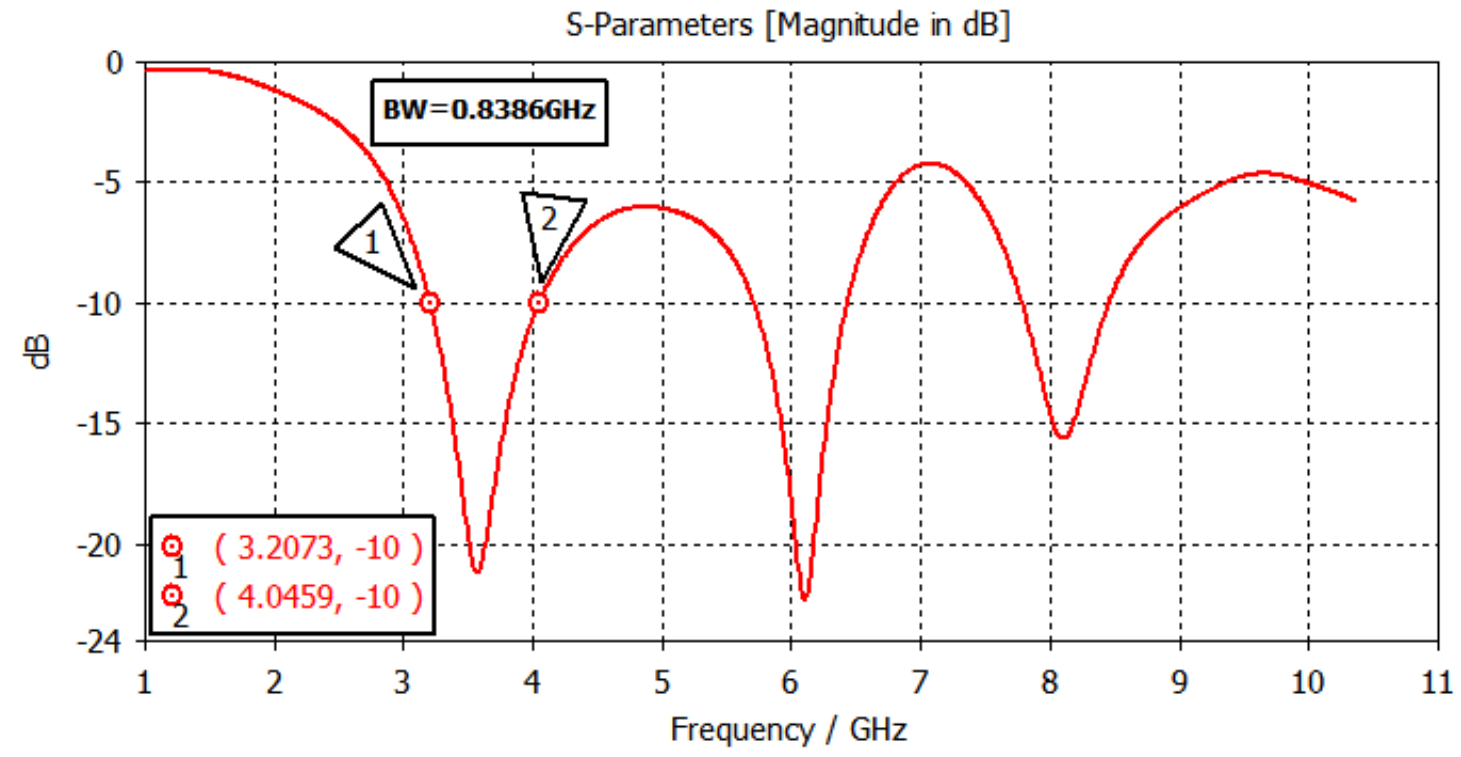

Fig. 1 Frequency vs. reflection coefficient $\left(\mathrm{S}_{11}\right)$ graph, when outer radius $\mathrm{R}=8.89 \mathrm{~mm}$ and Inner radius $r=6.26 \mathrm{~mm}$.

These initial parametric values made it possible to get a bandwidth by simulating our antenna. The obtained bandwidth was quite narrow but provided us with the values to initiate the design process. 


\section{Problem Definition}

The bandwidth of Ultra-wide band antenna depends on different design techniques e.g. patch shapes and feeding techniques. In this context, lots of configurations have been studied but the large size was the main problem to achieve the appropriate bandwidth. The antenna size and the bandwidth are dependent on each other. If bandwidth needs to be increased, then this requires the increase in the antenna size gradually. However we want antenna size to be compact and minimal.

Several antennas for suitable Ultra wideband applications have been tested such as stacked patch antenna wide slot antenna[27], tapered slot[28] and also other more antennas are designed and investigated in order to get the best fit antenna satisfying UWB requirements.

Some of the major issues of concern in the present available UWB antennas include the following:

1. Most of the designs are multifaceted which lead to complexity in the fabrication process.

2. Many tested designs have low band width and for achieving high band width, antenna size has to be increased implicitly [29].

3. Some designs have good band width but unsatisfactory antenna characteristics and also have greater VSWR values [30].

Considering the above mentioned problems, the aim of this work was research to obtain an antenna which is simple in design, have high bandwidth, satisfactory antenna characteristics, low VSWR and have compact antenna size too; all suitable for ultra wideband applications.

\section{Research Methodology}

As discussed above, in the design of an antenna there are many parameters. For a patch antenna, these include the parameters of substrate, patch and ground plane. A complex combination of them can give varying characteristics of beam width, bandwidth, radiation patterns, directivity and gain to an antenna. In this research we developed the research methodology for measuring the effect of the antenna parameters to identify most suitable values of them for meeting the requirements. In this approach of measurement engineering we explored the effect of individual parameters on antenna characteristics. At a single instant only one parameter is made to vary while othersremained constant. Following section shows this detailed analysis.

\section{Analysis on the Simulations of Antenna's Parameters}

The geometry of the proposed optimized antenna is shown in Fig 2 and Table 1. Antenna has been oriented in $x y$-plane whereas its normal lies in the direction of $z$-axis. The overall size of the antenna is $33 \mathrm{~mm} \times 28 \mathrm{~mm} \times 1.57 \mathrm{~mm}$, with FR4 substrate (lossy) having permittivity, $\varepsilon_{r}=$ 4.9.Various feed types can be used to feed the antenna including coplanar waveguide feed, probe feed, aperture coupled feed and microstrip line feed. Feed type used in this research work is 50 ohm microstrip line feed. 


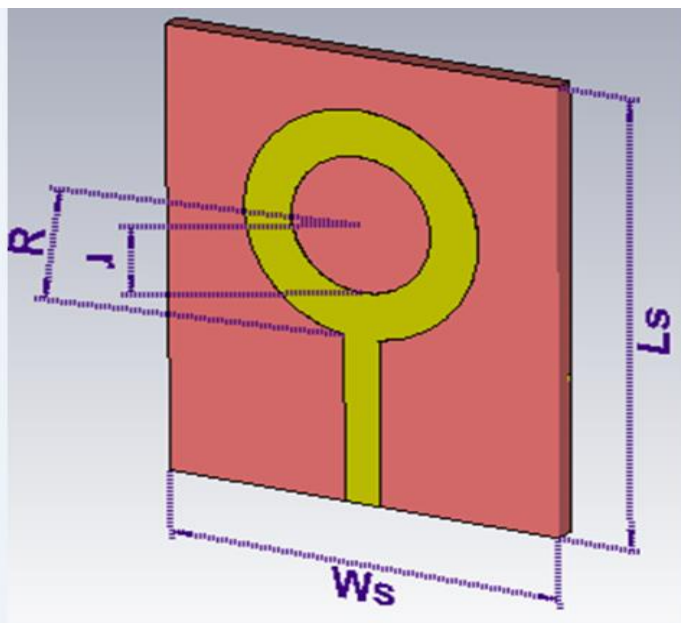

(a)

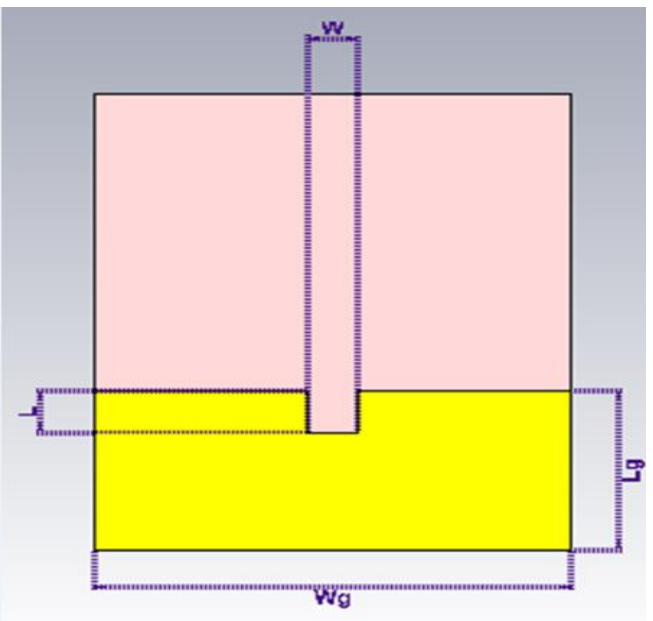

(b)

$W_{g}$

Fig. 2 Optimized and proposed antenna geometry

The designed values shown in Table 1 are final optimized values. However they were obtained after quite lengthy simulations.

Table 1 Antenna Parameters

\begin{tabular}{|l|l|c|l|}
\hline \multirow{2}{*}{ Substrate } & Parameter Label & $\begin{array}{l}\text { Parameters' } \\
\text { symbol }\end{array}$ & Dimension(mm) \\
\cline { 2 - 4 } & Substrate length & $L_{s}$ & 33 \\
\cline { 2 - 4 } Patch & Substrate width & $W_{S}$ & 28 \\
\cline { 2 - 4 } & Patch outer radius & $R$ & 8.4 \\
\cline { 2 - 4 } Feed & Patch inner radius & $r$ & 4 \\
\cline { 2 - 4 } & Feed line height & $F_{h}$ & 12.3 \\
\hline \multirow{2}{*}{ Ground } & Geed line width & $F_{w}$ & 2.55 \\
\cline { 2 - 4 } & Ground plane length & $L_{g}$ & 11.5 \\
\hline \multirow{2}{*}{ Square } & Square length & $L$ & 2.5 \\
\cline { 2 - 4 } & Square width & $W$ & 2.5 \\
\hline
\end{tabular}

Simulations and measurements performed to reach these values are presented in this section. Simulations were performed on the following parameters.

5.1 Effect of the patch outer radius $(\mathrm{R})$

5.2 Effect of the patch inner radius $(r)$

5.3 Effect of the ground plane length $\left(\mathrm{L}_{\mathrm{g}}\right)$

5.4 Effect of the ground width $\left(\mathrm{W}_{\mathrm{g}}\right)$ 
5.5 Effect of the feed line width $\left(\mathrm{F}_{\mathrm{w}}\right)$

5.6 Effect of the feed line height $\left(\mathrm{F}_{\mathrm{h}}\right)$

5.7 Effect of the truncation of the ground

\subsection{Effect of the patch outer radius $(R)$}

For the optimization of the patch, we have first optimized the outer radius of the circular patch, Simulations performed and as shown in Fig2 showed that by increasing the value of "R" we get a lower value of the lower frequency band of UWB, i.e. $f_{L}$ frequency. It was also noted in the simulations that after a very specific value (here $\mathrm{R}=8.3 \mathrm{~mm}$ ) if outer radius is increased, then there is no change in $\mathrm{f}_{\mathrm{L}}$ frequency. Simulations carried out are shown in Fig. 3. They show changes in reflection coefficient $\left(S_{11}\right)$ vs. entire frequency graph for different outer radius of the circular patch $(\mathrm{R})$.

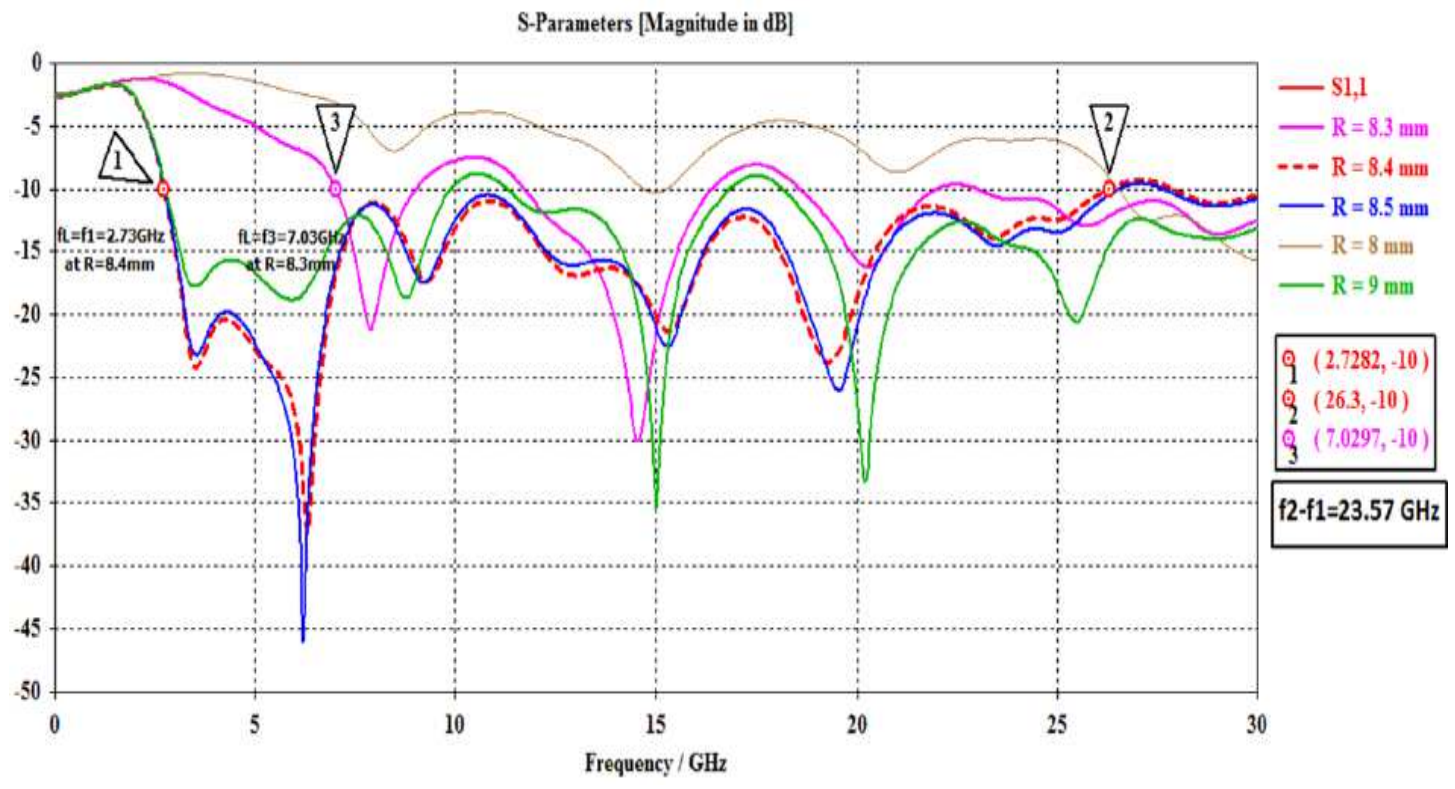

Fig 3 Frequency vs. reflection coefficient $\left(S_{11}\right)$ graph for different patch outer $\operatorname{radius}(\mathrm{R})$

It is clearly observable that in this design both the achieved bandwidth and lowest resonance frequency are dependent on the radius of the circular patch(R).From the Fig 3 it can be seen that when $\mathrm{R}=8.4 \mathrm{~mm}$ then the reflection coefficient is below then $-10 \mathrm{~dB}$ over the entire frequency band of interest. For values of $\mathrm{R} \geq 8.4 \mathrm{~mm}, \mathrm{~S}_{11}<-10 \mathrm{~dB}$ for the whole bandwidth of UWB.

Hence, considering the requirement of compact size, the optimized value of outer radius was taken as $\mathrm{R}=8.4 \mathrm{~mm}$. 


\subsection{Effect of the patch inner radius $(r)$}

For different values of the inner radius $r=5 \mathrm{~mm}, 4.75 \mathrm{~mm}$, $4 \mathrm{~mm}, 3 \mathrm{~mm}$ and $2 \mathrm{~mm}$, simulations were carried out to explore significant change in the reflection coefficient of antenna. This is as shown in Fig. 4.

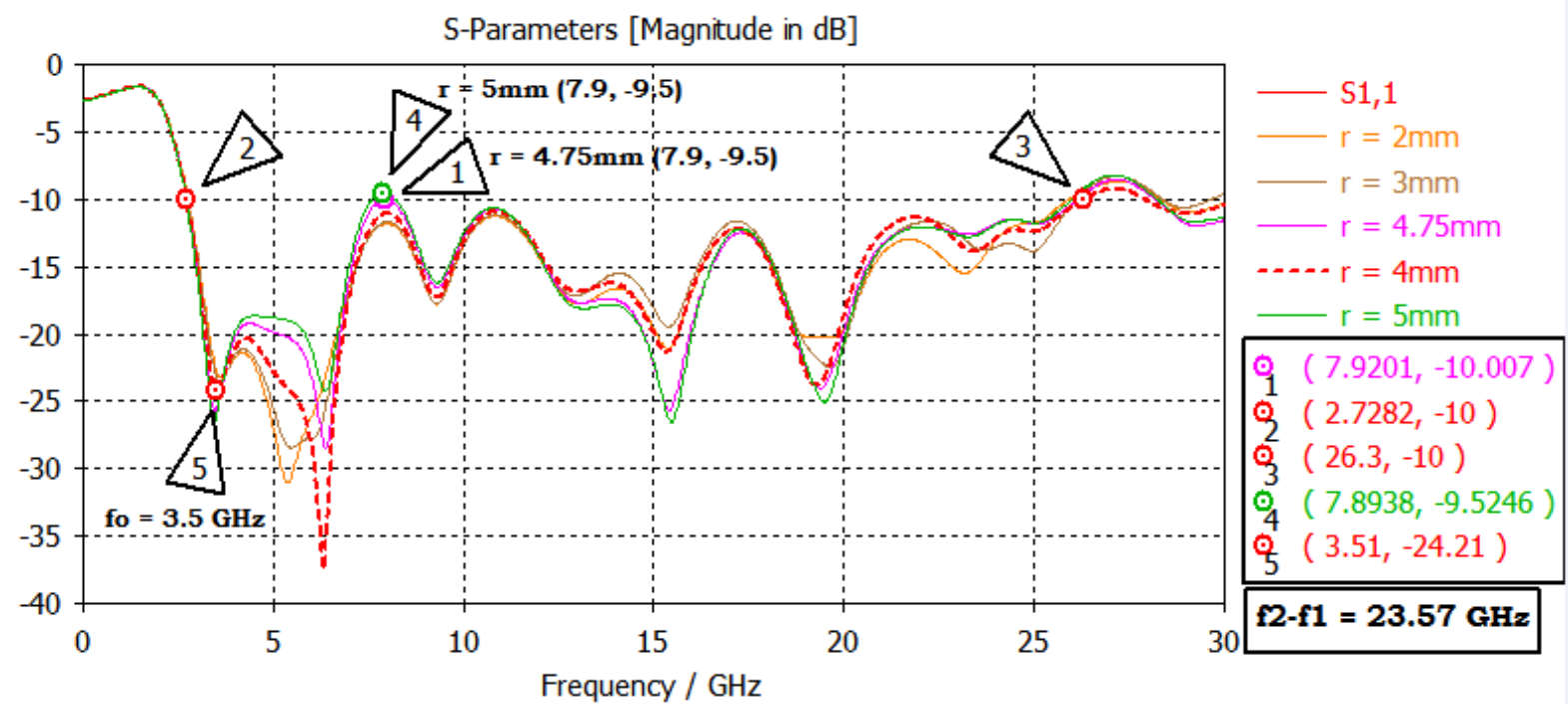

Fig. 4 Frequency vs. reflection coefficient graph for different patch inner Radius $(r)$.

From Fig 4, it is seen that changing effective inner radius of circular patch has significant effect on resonance frequency and return loss. Increasing of the effective inner patch radius doesn't change notably the other characteristics except reflection behavior of planar antenna. It is also seen in Fig 3that at marker $3(r=4.75 \mathrm{~mm})$ the reflection coefficient is exactly equal to $-10 \mathrm{~dB}$ and at marker $4(r=5 \mathrm{~mm})$ reflection coefficient is $-9.5 \mathrm{~dB}$. Hence below $r=$ $4.75 \mathrm{~mm}$ reflection coefficient would be less than $-10 \mathrm{~dB}$ in magnitude and above $r=4.75 \mathrm{~mm}$ reflection coefficient would be greater than $-10 \mathrm{~dB}$ in magnitude. It is seen from the Fig 4that when $r=4 \mathrm{~mm}$ then the reflection coefficient is less than-10dB over the entire frequency band of interest and the resonating frequency is $3.5 \mathrm{GHz}$.

Hence, considering the requirement of compact size, the optimized value of patch inner radius was taken as $r=4 \mathrm{~m}$.

\subsection{Effect of the ground plane length $\left(l_{g}\right)$}

For different values of the ground plain length, $\mathrm{L}_{\mathrm{g}}=12.5 \mathrm{~mm}, 12 \mathrm{~mm}$ or $11.5 \mathrm{~mm}$ and $11 \mathrm{~mm}$, respective variations in the reflection coefficient were obtained. From the simulations it is concluded that as the value of $\mathrm{L}_{\mathrm{g}}$ is decreased, the antenna started behaving more effectively 
with respect to reflection coefficient $\left(S_{11}\right)$. The plot of Reflection coefficient $\left(S_{11}\right)$ vs. entire frequency graph for different ground plane length $\mathrm{L}_{\mathrm{g}}$ is provided in Fig 5 .

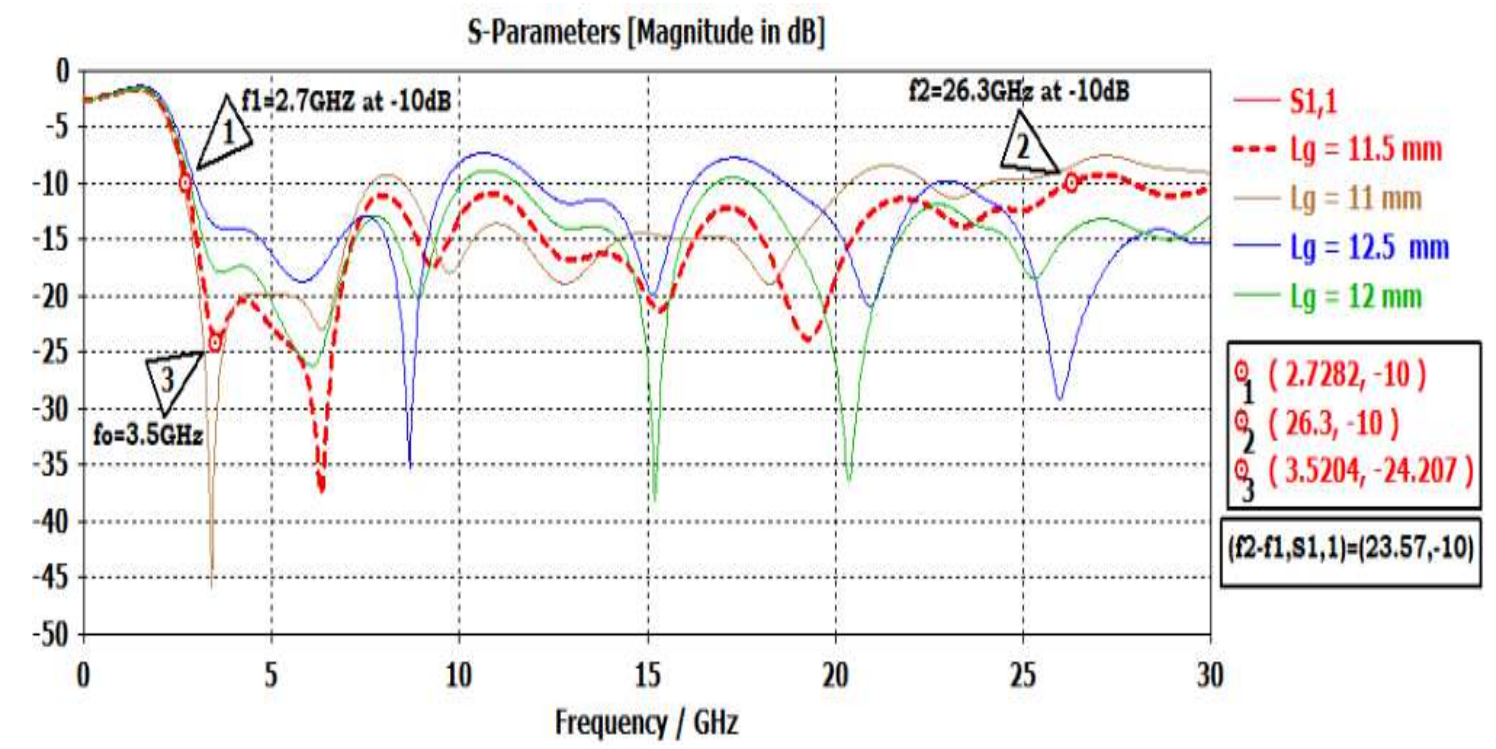

Fig. 5 Frequency vs. reflection coefficient graph for different ground plane length $\left(L_{g}\right)$

From the graph it is seen that the changing ground plane length has also significant effect on $\mathrm{f}_{\mathrm{L}}$ and $\mathrm{f}_{\mathrm{R}}$.It is observable from Fig 4 that when $\mathrm{L}_{\mathrm{g}}=11.5 \mathrm{~mm}$ then the reflection coefficient $\mathrm{S}_{11}<-10 \mathrm{~dB}$ over the entire frequency band of interest and the resonating frequency is 3.5 $\mathrm{GHz}$. At lower value of $\mathrm{L}_{\mathrm{g}}, \mathrm{S}_{11}$ is not consistent to be less than $-10 \mathrm{~dB}$.

Hence, considering the requirement of compact size, the optimized value of ground plane length was taken as $\mathrm{L}_{\mathrm{g}}=11.5 \mathrm{~mm}$.

\subsection{Effect of the ground plan width $\left(W_{g}\right)$}

In this simulation, effect of the ground plane width on the reflection behavior of the proposed antenna was explored for different values of the ground plane width $\mathrm{Wg}=28 \mathrm{~mm}$, $24.5 \mathrm{~mm}$ and $22 \mathrm{~mm}$. It was investigated that as $\mathrm{Wg}$ was reduced, a corresponding change appeared in the reflection coefficient of antenna. For $\mathrm{Wg}=28 \mathrm{~mm}$, provided the best behavior of proposed antenna. At this specific value we obtained $\mathrm{S}_{11}=-11.06 \mathrm{~dB}$. This showed that it is a good selection for the performance of antenna. The simulations are shown in Fig 6. 


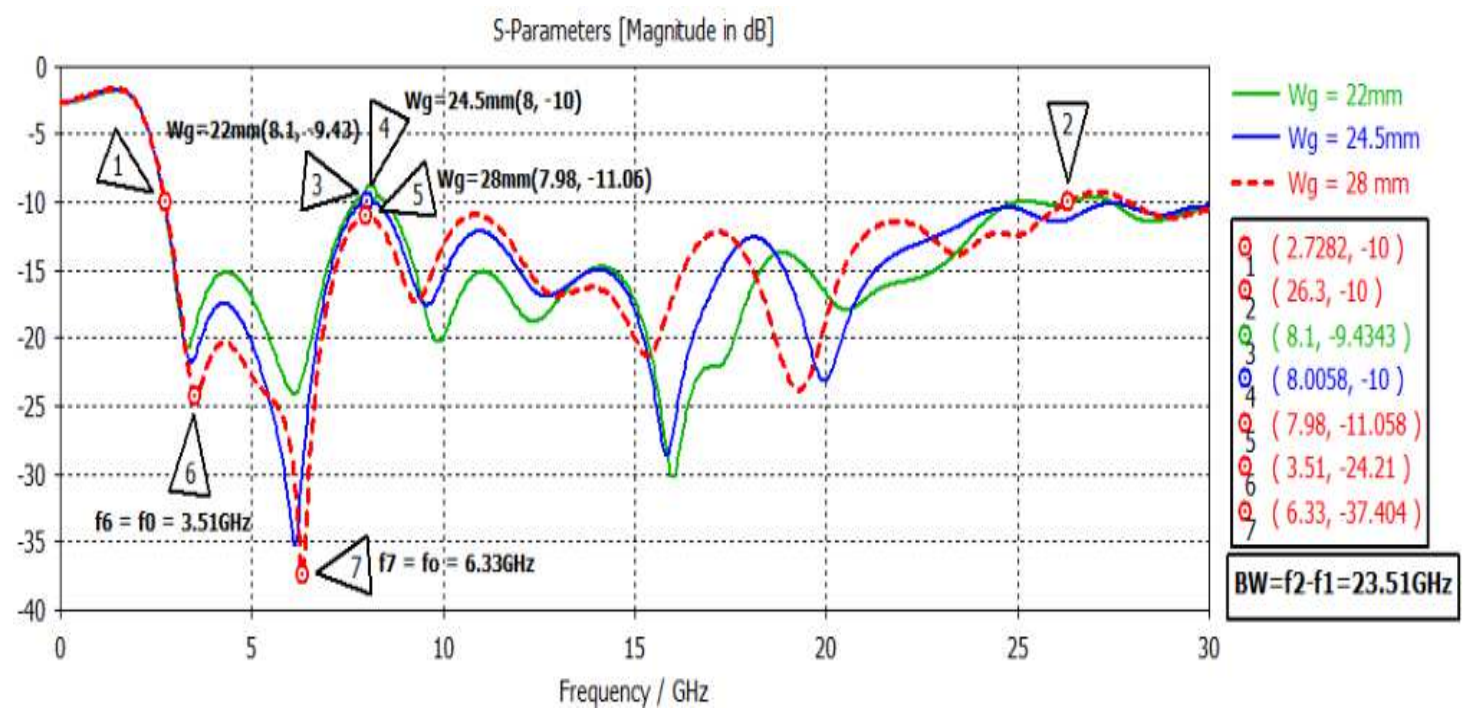

Fig. 6 Frequency vs. reflection coefficient graph for different values of ground plan width $\left(\mathrm{W}_{\mathrm{g}}\right)$.

From the graph it is very clear that there is no change in $\mathrm{f}_{\mathrm{L}}$ as the value of ground plan width in increased but only there was improvement in reflection coefficient of antenna as shown by marker 3,4and 5 in Fig 5.It was measured that when $\mathrm{Wg}=28 \mathrm{~mm}$ then the reflection coefficient was less than $-10 \mathrm{~dB}$ over the entire frequency band of interest and at this value maximum band width was obtained. At $\mathrm{W}_{\mathrm{g}}=24$ mmreflection coefficient was exactly equal to $10 \mathrm{~dB}$; so this value was measured to be a boundary value for the improvement of reflection coefficient. If $\mathrm{Wg}$ is increased above $24 \mathrm{~mm}$, good reflection coefficient was obtained and below this value there was poor reflection coefficient.

Hence, considering the requirement of compact size, the optimized value of ground plane width was taken asWg $=28 \mathrm{~mm}$.

\subsection{Effect of feed-height $\left(F_{h}\right)$}

For different values of the feed width, $\mathrm{F}_{\mathrm{h}}=$ $12.7 \mathrm{~mm}, 12.5 \mathrm{~mm}, 12.3 \mathrm{~mm}, 12 \mathrm{~mm}, 11.7 \mathrm{~mm}$. Simulations were carried out to measure that increase in the feed-line height, good performance of antenna with respect to its reflective behavior was obtained. This behavior increased as feed height was increased from its appropriate value. Simulations are shown in Fig. 7. 


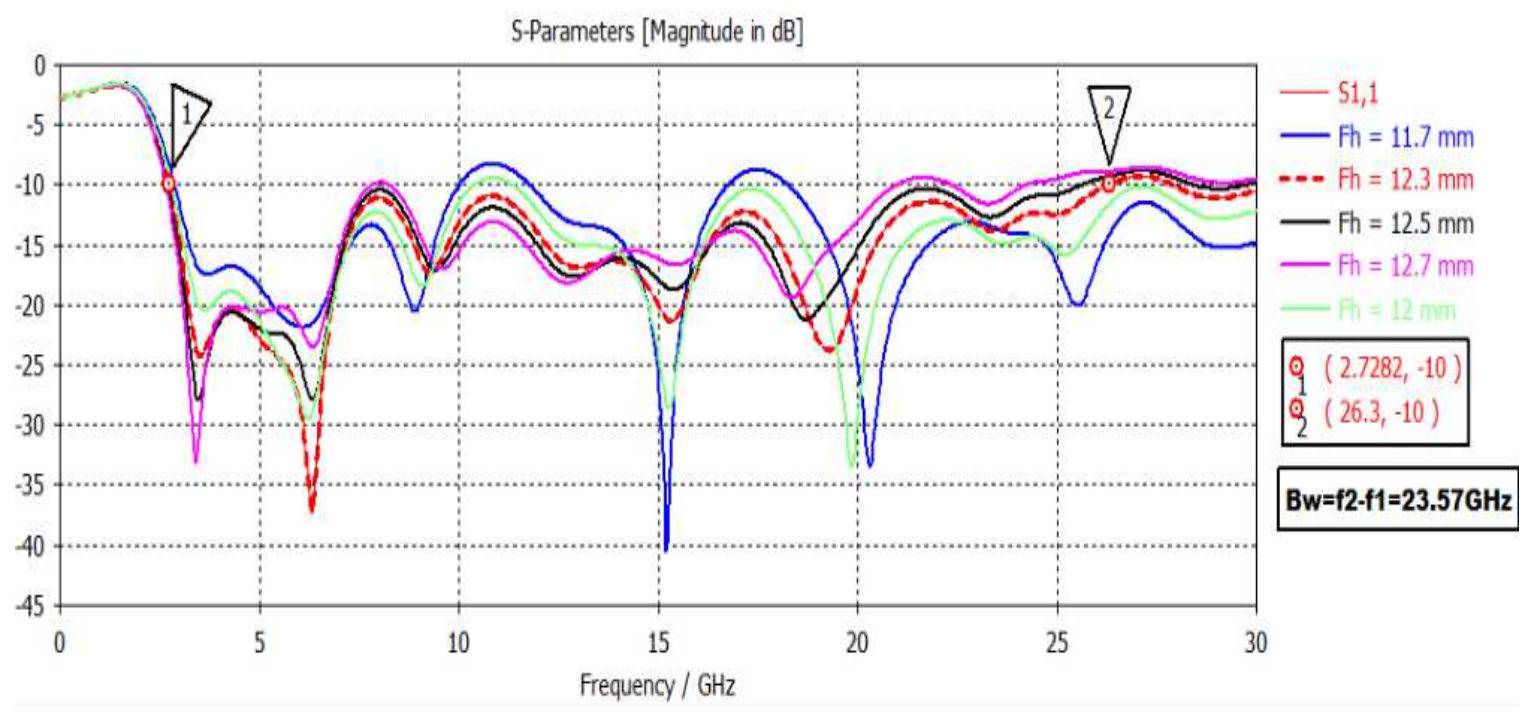

Fig. 7 Frequency vs. reflection coefficient graph for different values of feed height $\left(F_{h}\right)$

\subsection{Effect of Feed-line Width $\left(F_{w}\right)$}

For different values of the feed width, $\mathrm{F}_{\mathrm{w}}=2.55 \mathrm{~mm}, 3 \mathrm{mmand} 2 \mathrm{mmit}$ wasmeasured that as the feed-line width was increased from $2 \mathrm{~mm}$ to $2.5 \mathrm{~mm}$ good performance of antenna was obtained with respect to its reflective behavior. Simulations of these measurements analysis are shown in Fig 8.

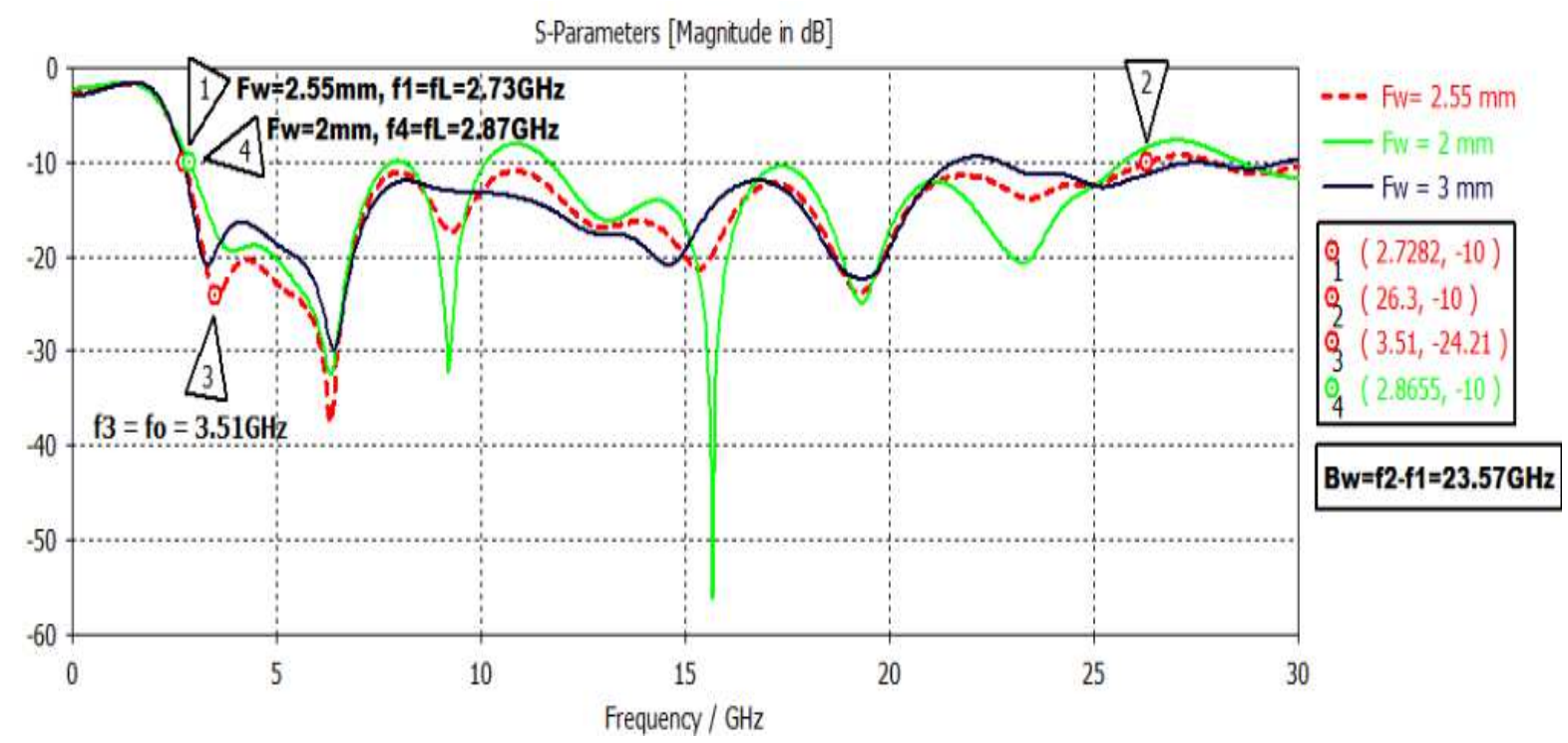

Fig. 8 Frequency vs. reflection coefficient graph for different values of feed width $\left(\mathrm{F}_{\mathrm{w}}\right)$. 
Fig 8, also investigated that the changing feed-line width has effect on resonance frequency $\left(\mathrm{f}_{\mathrm{r}}\right)$ and $\mathrm{f}_{\mathrm{L}}$.

Hence, considering the requirement of compact size, the optimized value of ground plane width was taken as $\mathrm{F}_{\mathrm{w}}=2.55 \mathrm{~mm}$.

\subsection{Effect of Truncation of the ground plane}

There is a very useful and effective technique for reducing the reflection coefficient. This is done by truncating the ground plane into rectangular or square shape geometry. This behavior of antenna is simulated and measured in this section.

\subsubsection{By square shape}

Ground plan was truncated by different values into a square shape geometry, i.e.L $\times \mathrm{W}=$ $(4 \times 4) \mathrm{mm}^{2}, \quad \mathrm{~L} \times \mathrm{W}=(3.5 \times 3.5) \mathrm{mm}^{2}, \quad \mathrm{~L} \times \mathrm{W}=(3.0 \times 3.0) \mathrm{mm}^{2}, \quad \mathrm{~L} \times \mathrm{W}=(2.5 \times$ 2.5) $\mathrm{mm}^{2}, \mathrm{~L} \times \mathrm{W}=(1.5 \times 1.5) \mathrm{mm}^{2}, \mathrm{~L} \times \mathrm{W}=(1.0 \times 1.0) \mathrm{mm}^{2}$. Simulations have been performed by using all these values to achieve desired band width. Results show different range of bandwidth according to the dimensions of square shape as shown in Fig 9.

S-Parameters [Magnitude in $\mathrm{dB}$ ]

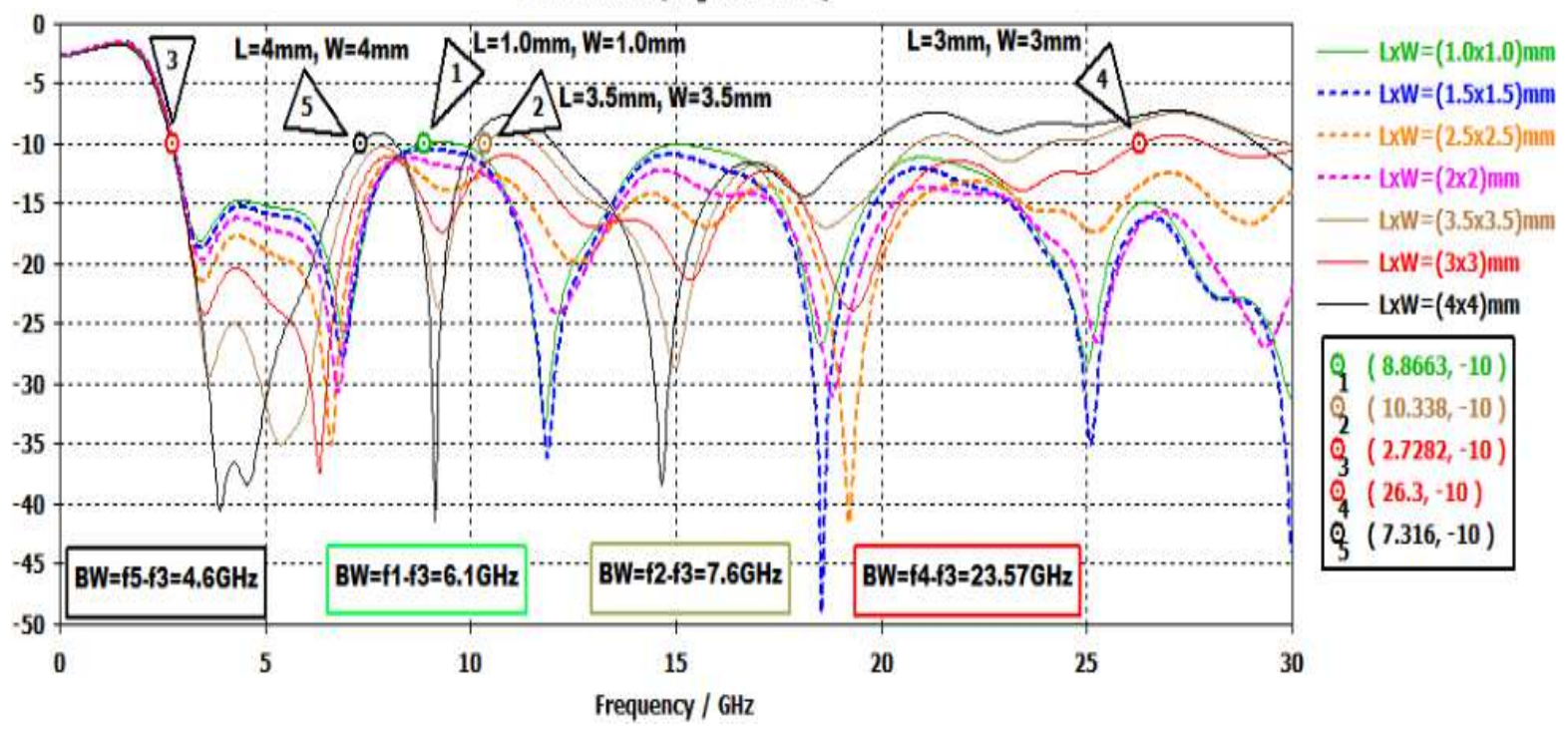

Fig. 9 Frequency vs. reflection coefficient graph for different dimension of square shape ground plain

Simulations in Fig. 9 showed that $\mathrm{f}_{\mathrm{L}}$ remained constant for all the different dimensions of square shaped ground plane while reflection coefficient was less than $-10 \mathrm{~dB}$ and $\mathrm{f}_{\mathrm{H}}$ on each curve varied. Bandwidth was increased as we dimensions of square were decreased. When the dimensions of square shaped ground plane were madeL $\times \mathrm{W}=(2.5 \times 2.5) \mathrm{mm}^{2}$, the bandwidth was achieved up $28.7 \mathrm{GHz}$. The value of bandwidth continuously increased as dimension or areas of square were decreased but when the dimension was made $\mathrm{L} \times \mathrm{W}=(1.0 \times 1.0) \mathrm{mm}^{2}$ 
then again bandwidth started decreasing. This behaviour and relationship of bandwidth against the dimensions of ground plane are summarized in Table 2.

Table 2. Bandwidth values for various Dimensions of antenna, when truncation is performed by Sqare shape.

\begin{tabular}{|c|c|c|c|}
\hline S. NO. & $\begin{array}{c}\text { Dimension } \\
(\mathbf{m m})\end{array}$ & $\begin{array}{c}\text { Area } \\
\left(\mathbf{m m}^{\mathbf{2}}\right)\end{array}$ & $\begin{array}{c}\text { Bandwidth }(\mathbf{B W}) \\
(\mathbf{G H z})\end{array}$ \\
\hline 1 & $4 \times 4$ & 16 & 3.59 \\
\hline 2 & $3.5 \times 3.5$ & 12.25 & 7.61 \\
\hline 3 & $3 \times 3$ & 9 & 23.57 \\
\hline 4 & $2.5 \times 2.5$ & 6.25 & 29.23 \\
\hline 5 & $2 \times 2$ & 4 & $\mathrm{BW}>30 \mathrm{GHz}$ \\
\hline 6 & $1.5 \times 1.5$ & 2.25 & $\mathrm{BW}>30 \mathrm{GHz}$ \\
\hline 7 & $1 \times 1$ & 1 & 6.1 \\
\hline
\end{tabular}

\subsubsection{By rectangular shape}

Just like it was done for square shaped ground plane, here the ground plan was truncated by different values of rectangular shape dimensions, i.e. $\mathrm{L} \times \mathrm{W}=(3 \times 1.5) \mathrm{mm}^{2},(1.5 \times$ 3) $\mathrm{mm}^{2},(3 \times 3.5) \mathrm{mm}^{2},(3.5 \times 3) \mathrm{mm}^{2},(3.5 \times 2.5) \mathrm{mm}^{2}$ and $(0.75 \times 1.5) \mathrm{mm}^{2}$. Simulations are shown in Fig 10.

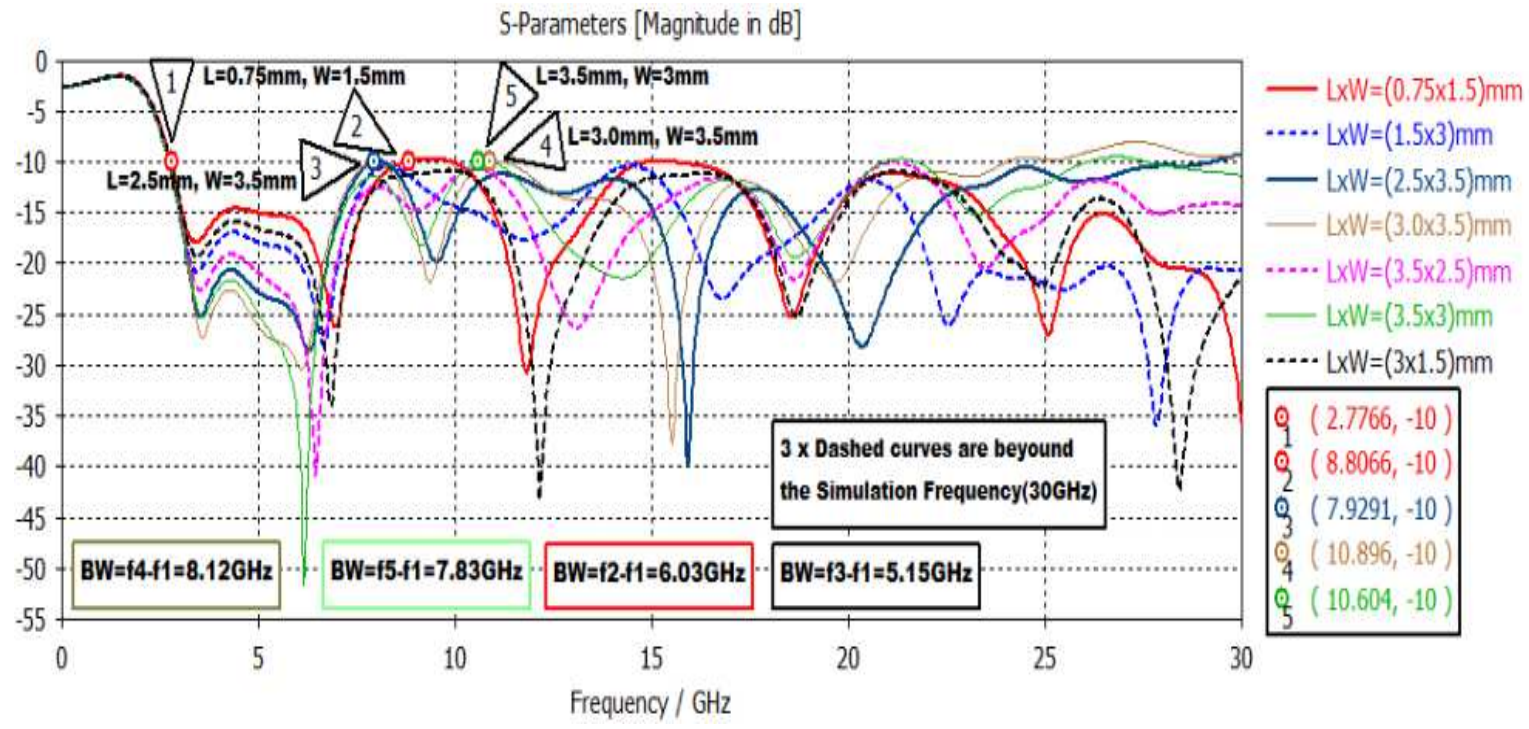

Fig.10 Frequency vs. reflection coefficient graph for different dimension of rectangle before optimization 
Simulations in Fig 10 showed that $\mathrm{f}_{\mathrm{L}}$ remained constant for all the different dimensions of rectangular shaped ground plane while reflection coefficient was less than $-10 \mathrm{~dB}$ and $\mathrm{f}_{\mathrm{H}}$ on each curve varies. Bandwidth was decreased as the dimensions or area of rectangle was decreased. But when the dimensions of recangle shaped ground plane were made $\mathrm{L} \times \mathrm{W}=(2.5 \times$ 3.5) $\mathrm{mm}^{2}, \mathrm{~L} \times \mathrm{W}=(1.5 \times 3.0) \mathrm{mm}^{2}$ the increment in bandwidth were achieved beyond the simulation frequncy $(30 \mathrm{GHz})$. when we continuously decreases the dimension or area of rectangle then at $\mathrm{L} \times \mathrm{W}=(075.5 \times 1.5) \mathrm{mm}^{2}$ the value of bandwidth again decreased. This behaviour and relationship of bandwidth against the dimensions of ground plane are summarized in Table 3.

Table 3. Bandwidth values for various dimensions of antenna, when truncation is performed by rectangle shape

\begin{tabular}{|c|c|c|c|}
\hline S.NO & Dimension(mm) & $\begin{array}{c}\text { Area } \\
(\mathbf{m m} 2)\end{array}$ & $\begin{array}{c}\text { Bandwidth }(\mathbf{B W}) \\
(\mathbf{G H z})\end{array}$ \\
\hline 1 & $3.5 \times 3$ & 10.5 & 8.16 \\
\hline 2 & $3 \times 3.5$ & 10.5 & 7.86 \\
\hline 3 & $3.5 \times 2.5$ & 8.75 & 5.19 \\
\hline 4 & $2.5 \times 3.5$ & 8.75 & $\mathrm{BW}>30 \mathrm{GHz}$ \\
\hline 5 & $1.5 \times 3.0$ & 4 & $\mathrm{BW}>30 \mathrm{GHz}$ \\
\hline 6 & $3.0 \times 1.5$ & 4 & $\mathrm{BW}>30 \mathrm{GHz}$ \\
\hline 7 & $0.75 \times 1.5$ & 1.125 & 6.03 \\
\hline
\end{tabular}

Simulating for both rectangular and square ground plane shows that high bandwidth can be achieved by either of them. But comparatively square shaped ground plane provided higher bandwidth and practically they are easier to be fabricated. Hence therefore square shaped ground plane structure was considered for the final design.

\section{Results}

Simulations were carried out for bandwidth measurements using both non-optimized and optimized truncated ground plane antenna structures. The simulation results for $\mathrm{S}_{11}(\mathrm{~dB})$ are shown in Fig. 11 


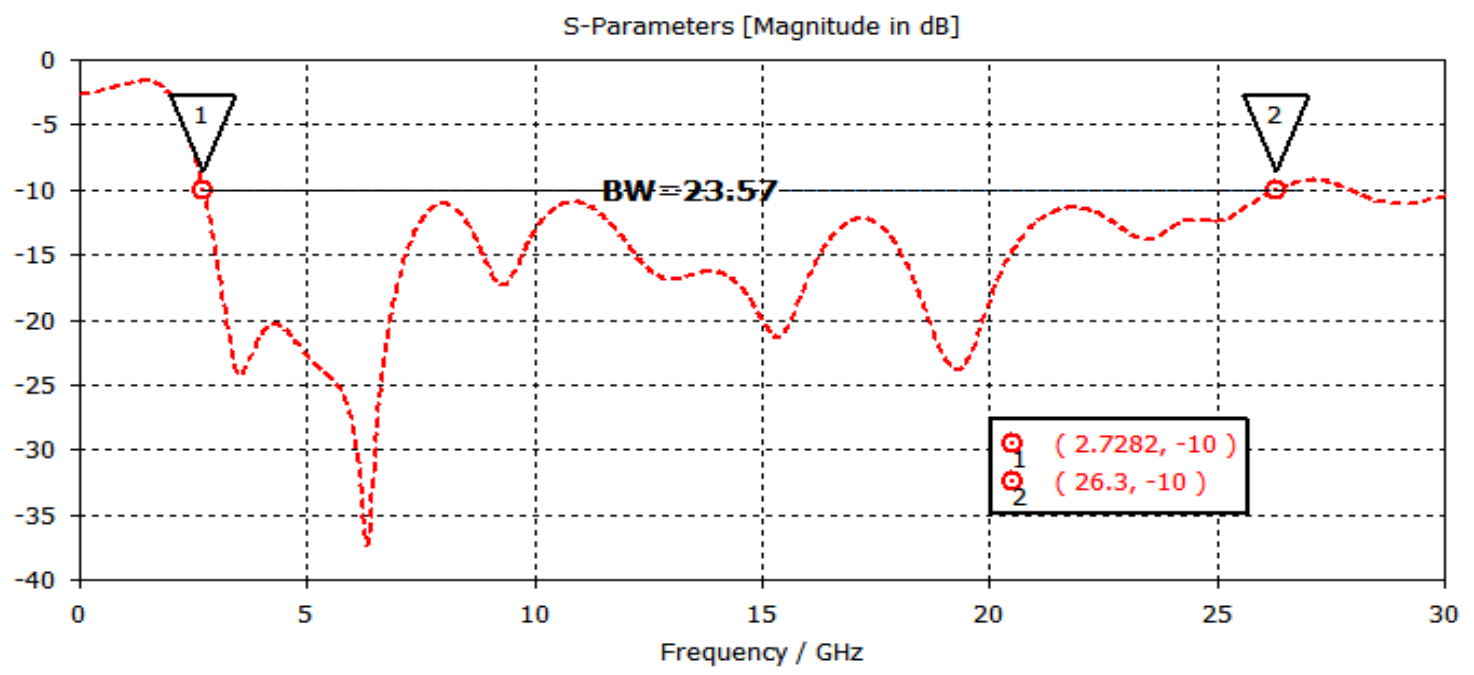

Fig. 11 Simulated result for non optimized truncated ground plane, $S_{11}$ parameter magnitude in $\mathrm{dB}$

In Fig 12 are shown the simulation results when the truncated ground plane optimized to square shape was used. This clearly shows the increase in bandwidth as compared to nonoptimized truncated plane

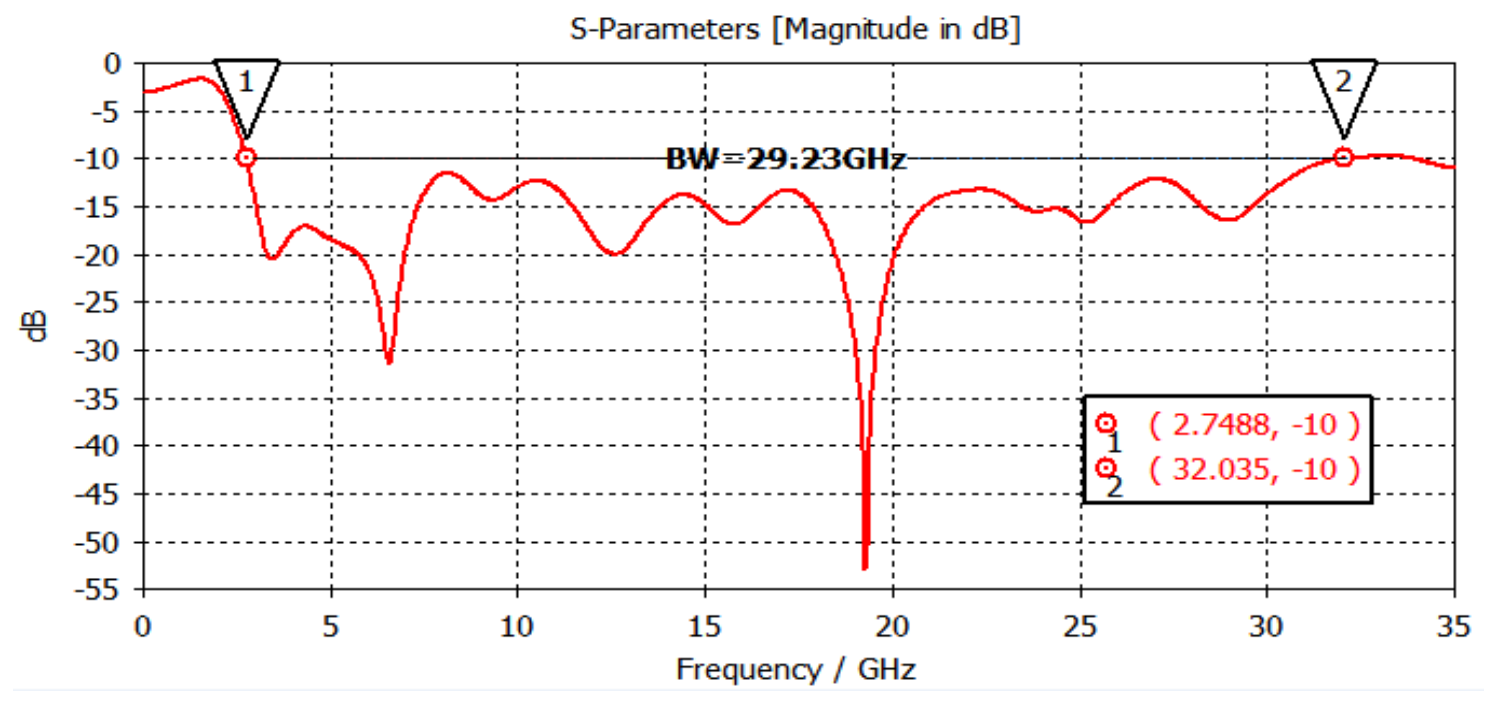

Fig. 12 Simulated result for optimized truncated round plane, $S_{11}$ parameter magnitude in $d B$

The vector network analyzer (VNA) was used to verify the simulated result. These are shown in Fig. 12 


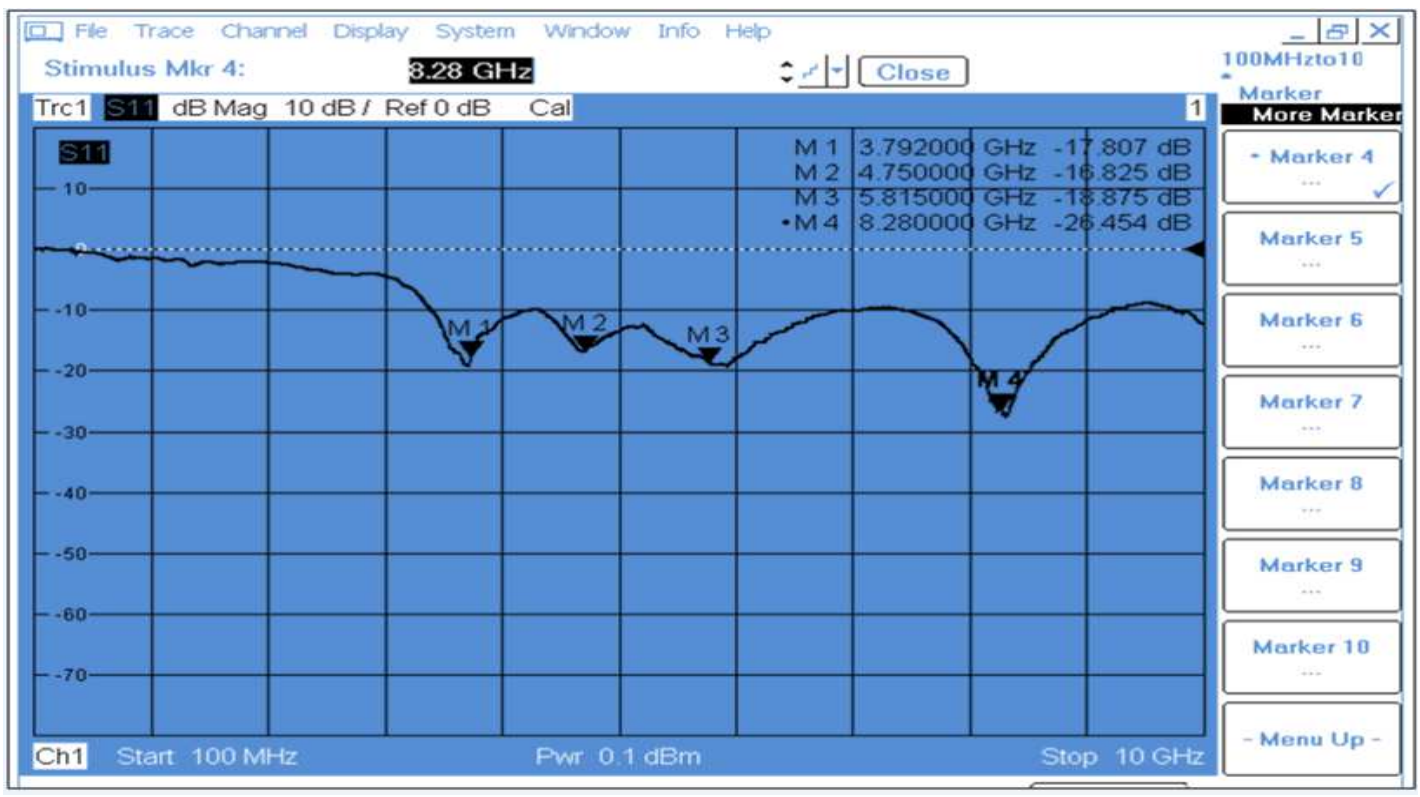

Fig. 13 Measured result from $400 \mathrm{MHz}$ to $10 \mathrm{GHz}, \mathrm{S}_{11}$ parameter magnitude in $\mathrm{dB}$

The directivity of the optimized antenna and voltage standing wave ratio are shown in Fig 14 and Fig 15 respectively.

Farfield Directivity Abs (Theta $=90$ )

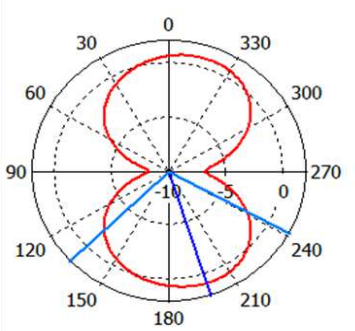

Phi / Degree vs. dBi

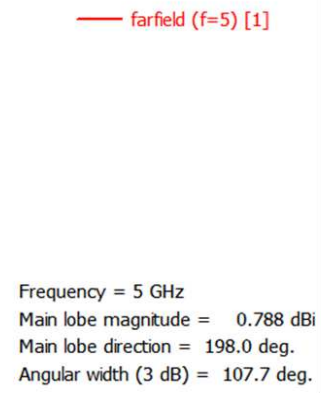

(a)

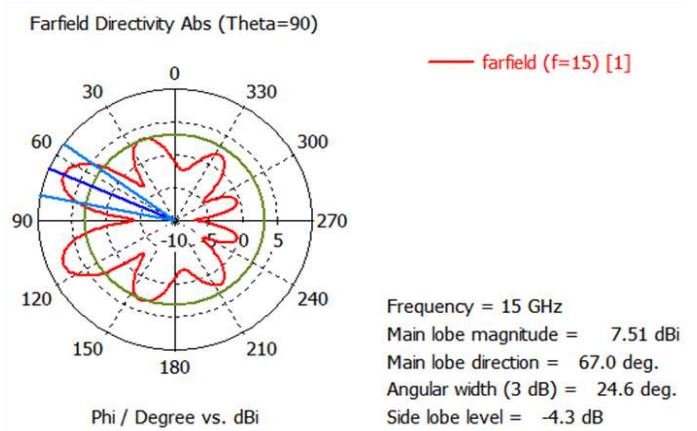

(b)

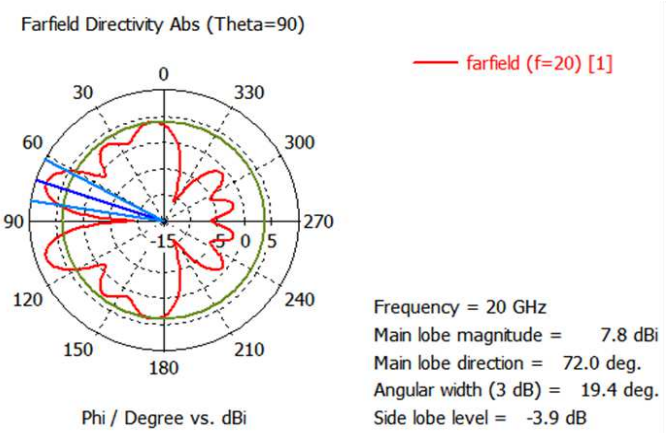

(c)

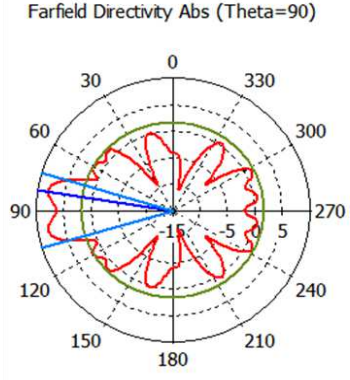

Phi / Degree vs. dBi
Main lobe direction $=67.0 \mathrm{deg}$. Side lobe level $=-4.3 \mathrm{~dB}$

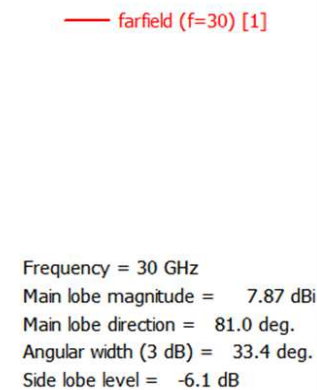

(d)

Fig. 14 Directivity of optimized Antenna at (a) $5 \mathrm{GHz}$, (b) $15 \mathrm{GHz}$, (c) $20 \mathrm{GHz}$ and (d) $30 \mathrm{GHz}$ 


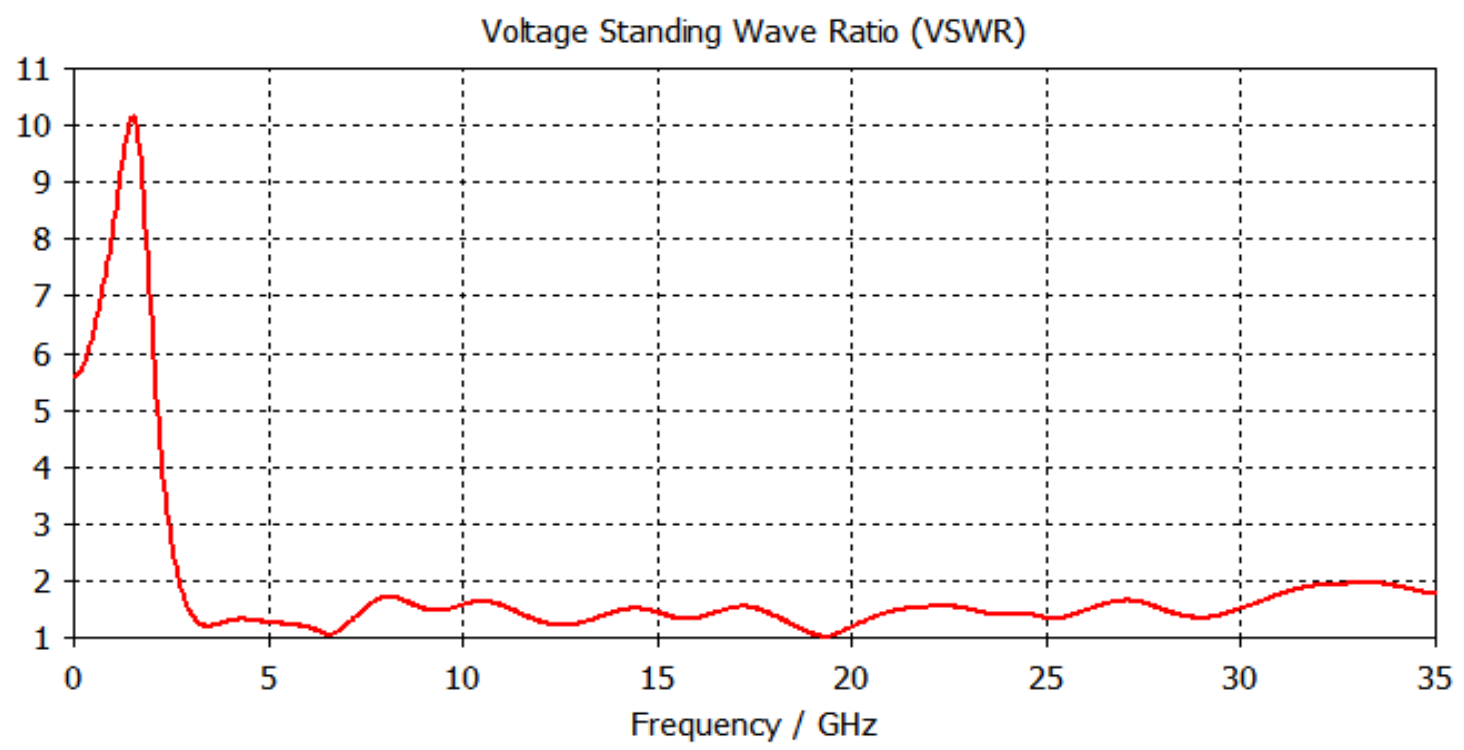

Fig. 15 Voltage Standing Wave Ratio graph for proposed optimized Antenna

Since in the proposed antenna the primary concern was increase in bandwidth along with moderate structure size of antenna, below in Table 4 some previous reported antennas are listed with the comparison in term of size and bandwidth with this design.

Table 4. Bandwidth values for various dimensions of some previously presented antennas

\begin{tabular}{|c|c|c|c|}
\hline Refrences & $\begin{array}{c}\text { Size }(\mathbf{W x L}) \\
(\mathbf{m m})^{\mathbf{2}}\end{array}$ & $\begin{array}{c}\text { Operating band } \\
\left(\boldsymbol{f}_{\boldsymbol{H}}-\boldsymbol{f}_{\mathbf{L}}\right) \mathbf{G H z}\end{array}$ & $\begin{array}{c}\text { Band Width } \\
(\mathbf{B W}) \mathbf{G H z}\end{array}$ \\
\hline$[7]$ & $39 \times 36.6$ & $3.5-17$ & 13.5 \\
\hline$[8]$ & $32 \times 25$ & $2.85-15.25$ & 12.4 \\
\hline$[9]$ & $30 \times 30$ & $0.020-20$ & 19.98 \\
\hline$[10]$ & $60 \times 55$ & $2.0-14.65$ & 12.65 \\
\hline$[11]$ & $22 \times 25$ & $3.1-12.18$ & 9.08 \\
\hline$[12]$ & $25 \times 35$ & $3.54-12$ & 8.46 \\
\hline$[23]$ & $17 \times 25$ & $2.1-15.8$ & 13.7 \\
\hline $\begin{array}{c}\text { Proposed Antenna (non- } \\
\text { optimized ground plane })\end{array}$ & $33 \times 28$ & $2.73-26.3$ & 23.57 \\
\hline $\begin{array}{c}\text { Proposed Antenna }(\text { optimized } \\
\text { ground plane })\end{array}$ & $33 \times 28$ & $2.75-32.04$ & 29.3 \\
\hline
\end{tabular}




\section{Conclusions}

In this paper, we have successfully designed and developed a compact in size and high bandwidth UWB antenna using simulations and measurement engineering. In this study, in-depth simulations were carried out to show the design process and setting of antenna parameters. The final antenna structure is engineered to be compatible in low volume requirements such as in body area networks and others.

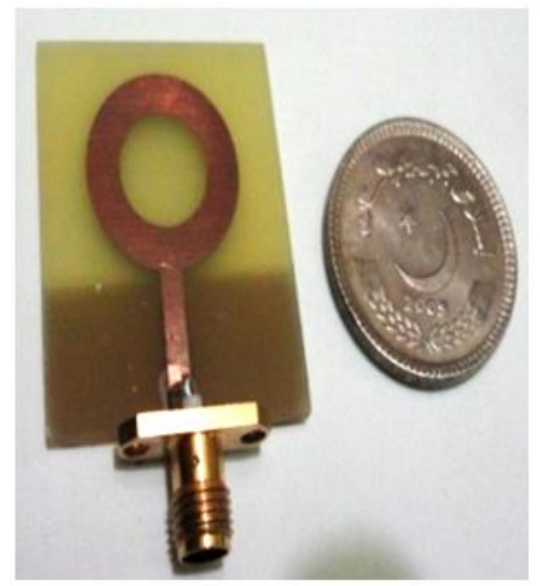

(a)

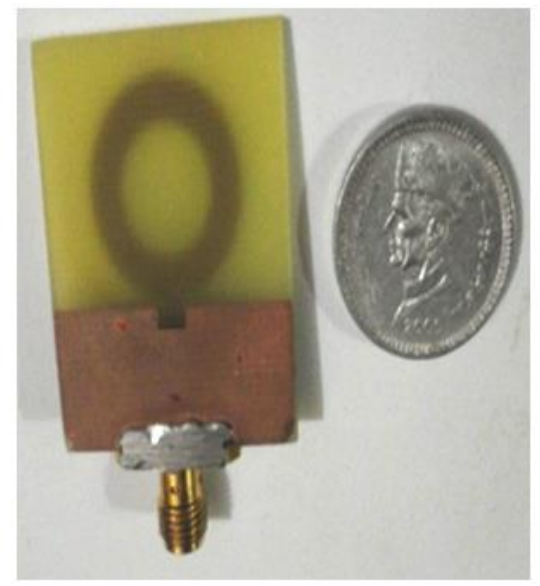

(b)

Fig. 16 (a) Front side (b) Back side of fabricated antenna

\section{Declarations}

Funding (The author(s) received no specific funding for this work)

Conflicts of interest/Competing interests (NO authors have competing interests)

Availability of data and material (All data are fully available without restriction)

Code availability (Available) 
Authors' contributions (All authors contributed to the study conception and design. Material preparation, data collection and analysis were performed by [Syed Zeeshan Ali] and [Ikram e Khuda]. The first draft of the manuscript was written by [Syed Zeeshan Ali] and all authors commented on previous versions of the manuscript. All authors read and approved the final manuscript)

\section{References}

[1] KHUDA, I., \& MOINUDDIN, M. (2018). Realization of a Finite Impulse Response Pulse Shaping Filter for Ultra-Wide Band Electronic Communication System. Sindh University Research JournalSURJ (Science Series), 50(01), 33-40.

[2] Khuda, I. E., \&Raza, K. (2016, December). Design of adaptive infinite impulse response digital filter for Ultra-wide band optimum pulse shaping. In 2016 19th International Multi-Topic Conference (INMIC) (pp. 1-5). IEEE.

[3] Khuda, I. E. (2017). A comprehensive review on design and development of human breast phantoms for ultra-wide band breast cancer imaging systems. Engineering Journal, 21(3), 183-206.

[4] Sharma, N., Bhatia, S. S., Sharma, V., \&Sivia, J. S. (2020). An Octagonal Shaped Monopole Antenna for UWB Applications with Band Notch Characteristics. Wireless Personal Communications, 111(3), 1977-1997.

[5] Roy, B., Chowdhury, S. K., \& Bhattacharjee, A. K. (2019). Symmetrical hexagonal monopole antenna with bandwidth enhancement under UWB operations. Wireless Personal Communications, 108(2), 853-863.

[6] Ezuma, M. C., Subedi, S., \&Pyun, J. Y. (2015, January). Design of a compact UWB antenna for multi-band wireless applications. In 2015 International Conference on Information Networking (ICOIN) (pp. 456-461). IEEE.

[7] Rahman, N., Islam, M. T., Mahmud, Z., \& Samsuzzaman, M. (2018). The Broken-Heart Printed Antenna for Ultrawideband Applications: Design and Characteristics Analysis. IEEE Antennas and Propagation Magazine, 60(6), 45-51.

[8] Salamin, M. A., Ali, W., \& Zugari, A. (2019). Design and analysis of a miniaturized band-notched planar antenna incorporating a joint DMS and DGS band-rejection technique for UWB applications. Microsystem Technologies, 25(9), 3375-3385.

[9] Elhabchi, M., Srifi, M. N., \&Touahni, R. (2020). A novel modified U-shaped microstrip antenna for super wide band (SWB) applications. Analog Integrated Circuits and Signal Processing, 1-8.

[10] Mewara, H. S., Kumawat, R., \& Sharma, M. M. (2016, December). Design and analysis of an ultrawide band antenna consisting of extra radiating patch with bandwidth enhancement and band notch characteristics. In 2016 International Conference on Recent Advances and Innovations in Engineering (ICRAIE) (pp. 1-5). IEEE.

[11] Adam, A. A., Rahim, S. K. A., Tan, K. G., \& Reza, A. W. (2013). Design of 3.1-12 GHz printed elliptical disc monopole antenna with half circular modified ground plane for UWB application. Wireless Personal Communications, 69(2), 535-549.

[12] Bekasiewicz, A., \&Koziel, S. (2016). Compact UWB monopole antenna for internet of things applications. Electronics Letters, 52(7), 492-494.

[13] Zhu, J., Fox, J. J., Yi, N., \& Cheng, H. (2019). Structural Design for Stretchable Microstrip Antennas. ACS applied materials \& interfaces, 11(9), 8867-8877. 
[14] Mahouti, P. (2019). Design optimization of a pattern reconfigurable microstrip antenna using differential evolution and 3D EM simulation-based neural network model. International Journal of RF and Microwave Computer-Aided Engineering, 29(8), e21796.

[15] Ansari, J. A., Kumari, K., Singh, A., \& Mishra, A. (2013). Ultra wideband co-planer microstrip patch antenna for wireless applications. Wireless personal communications, 69(4), 1365-1378.

[16] Khuda, I. E. (2017). Modeling and simulation of UWB wave propagation for early detection of breast tumors in cancer dielectric imaging systems. Engineering Journal, 21(2), 237-251.

[17] Khuda, I. E. (2018). Feasibility of the Detection of Breast Cancer Using Ultra-Wide Band (UWB) Technology in Comparison with Other Screening Techniques. In UWB Technology and its Applications. IntechOpen.

[18] Yang, S. L. S., Kishk, A. A., \& Lee, K. F. (2008). Frequency reconfigurable U-slot microstrip patch antenna. IEEE Antennas and Wireless propagation letters, 7, 127-129.

[19] Wang, H., Huang, X. B., \& Fang, D. G. (2008). A single layer wideband U-slot microstrip patch antenna array. IEEE antennas and wireless propagation letters, 7, 9-12.

[20] Araujo, W. C., d'Assunção, A. G., \&Mendonça, L. M. (2010, May). Effect of square slot in microstrip patch antennas using artificial neural networks. In Digests of the 2010 14th Biennial IEEE Conference on Electromagnetic Field Computation (pp. 1-1).

[21] Mujahidin, I. (2014.). Directional $1900 \mathrm{MHz}$ Square Patch Ring Slot Microstrip Antenna for WCDMA JEEMECS. Journal of Electrical Engineering, Mechatronic and Computer Science), 1(2), 42-45, 2018.

[22] Li, Y., \& Li, W. A circular slot antenna with wide tunable and reconfigurable frequency rejection characteristic using capacitance loaded split-ring resonator for UWB applications. Wireless personal communications, 78(1), 137-149.

[23] Pannu, P., \& Sharma, D. K. (2020). A Low-Profile Compact Ultra-Wideband Antenna for Wireless Applications. In Micro-Electronics and Telecommunication Engineering, pp. 341-349. Springer, Singapore.

[24] Raza, K., Akhtar, S., \&Naqvi, H. A.(2014) .On the Design of Electromagnetically Coupled Microstrip Antenna. Asian Journal of Engineering, Sciences \& Technology, 4(1).

[25] Badjian, M. H., Chakrabarty, C. K., Hock, G. C., \& Devkumar, S.(August, 2008) . An impulse UWB patch antenna with integrated band pass filter." In 2008 6th National Conference on Telecommunication Technologies and 2008 2nd Malaysia Conference on Photonics, IEEE (pp. 166169.

[26] Azim, R., Mobashsher, A. T., \& Islam, M. T. (2013). UWB antenna with notched band at 5.5 GHz. Electronics Letters, 49(15), 922-924.

[27] Van den Brande, Q., Lemey, S., Vanfleteren, J., \& Rogier, H.( 2018) .Highly efficient impulse-radio ultra-wideband cavity-backed slot antenna in stacked air-filled substrate integrated waveguide technology." IEEE Transactions on Antennas and Propagation, 66(5), 2199-2209.

[28] Azim, R., Islam, M. T., \& Misran, N. (2011). Compact tapered-shape slot antenna for UWB applications. IEEE Antennas and Wireless Propagation Letters, 10, 1190-1193.

[29] Wu, J., Zhao, Z., Nie, Z., \& Liu, Q. H. (2014). A printed UWB Vivaldi antenna using stepped connection structure between slotted line and tapered patches." IEEE Antennas and Wireless Propagation Letters, 13, 698-701.

[30] Cruz, C. C., Costa, J. R., \& Fernandez, C. A. (2012) .Hybrid UHF/UWB antenna for passive indoor identification and localization systems.. IEEE Transactions on Antennas and Propagation, 61(1), 354-361. 


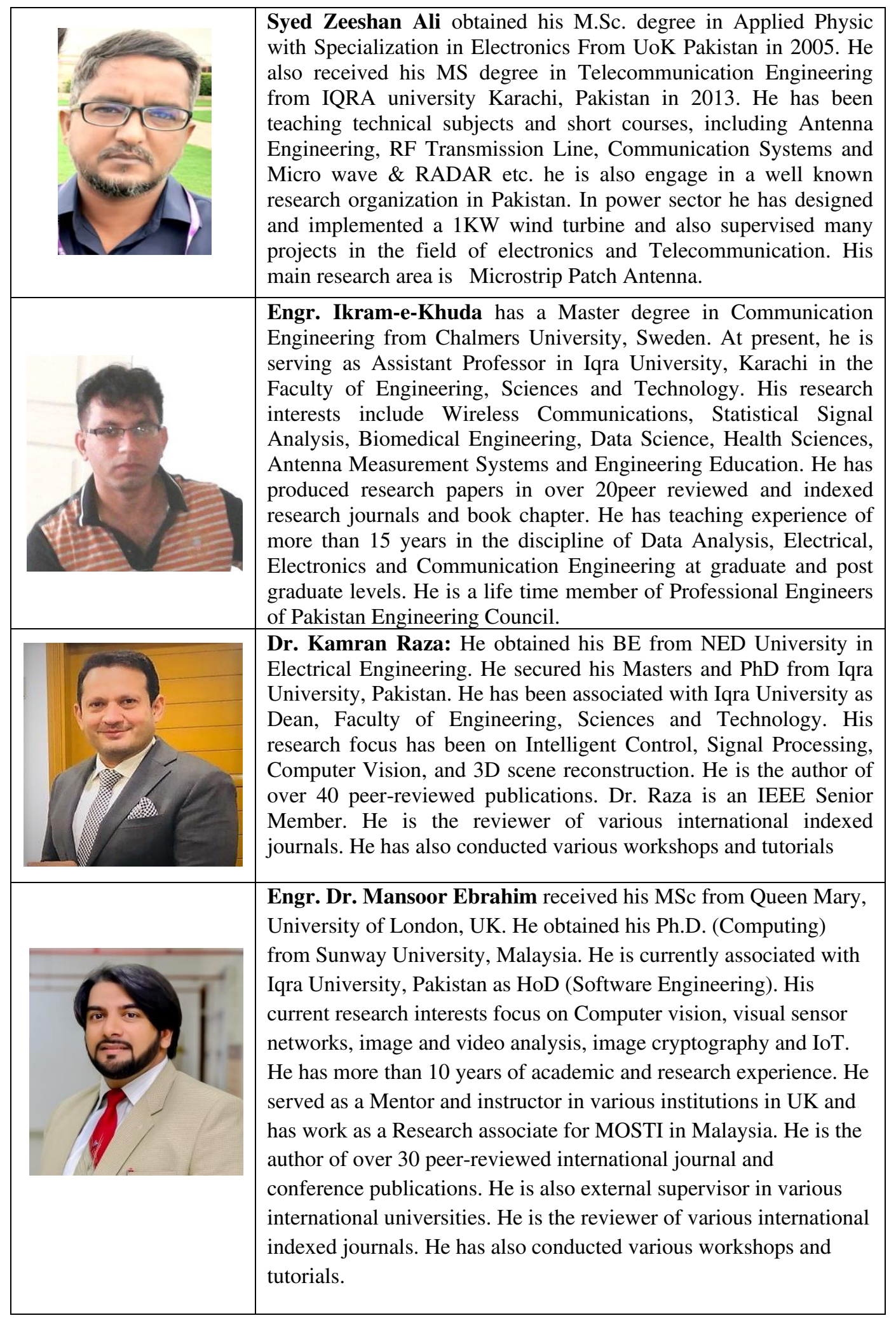


Figures

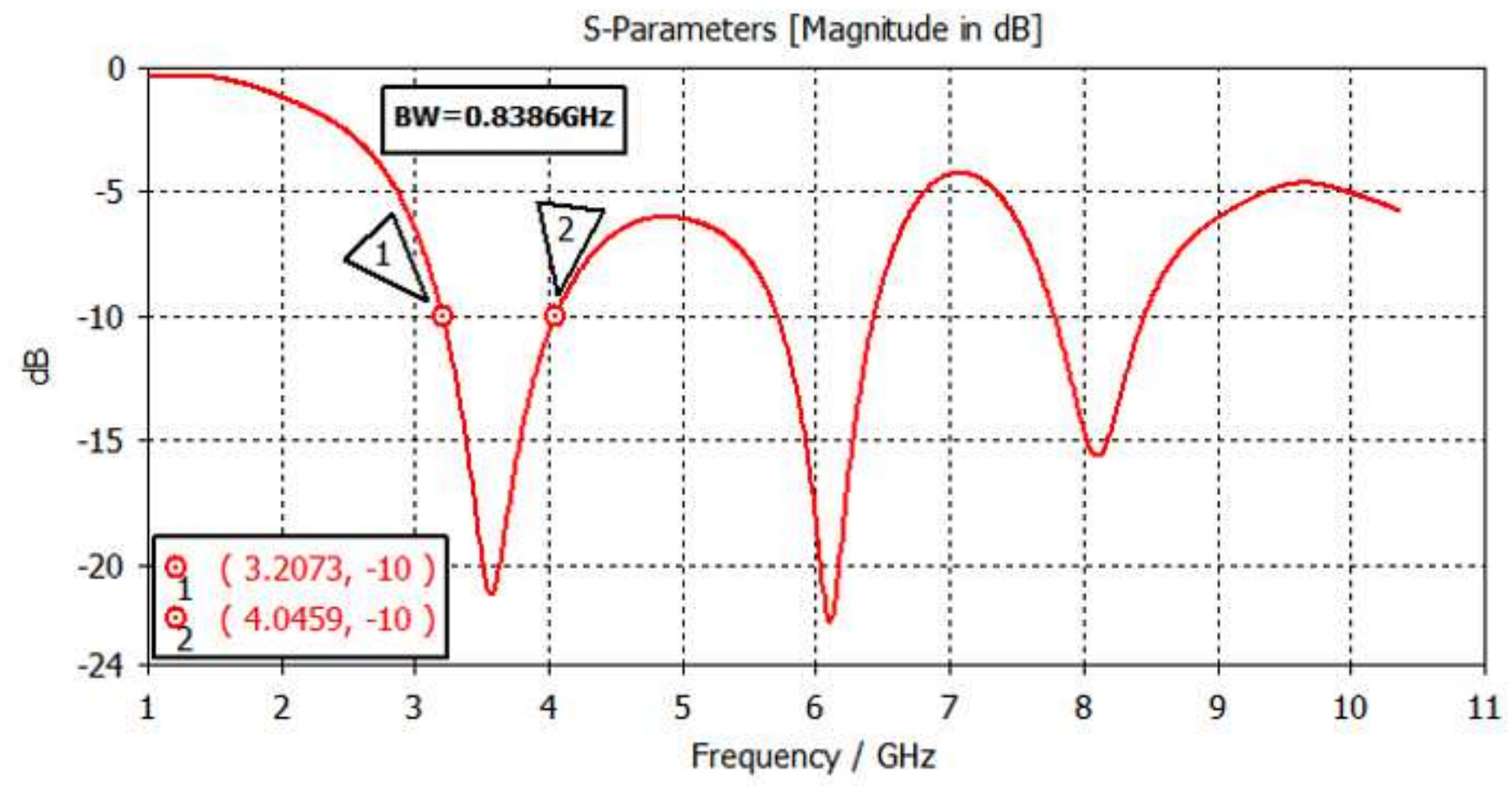

Figure 1

Frequency vs. reflection coefficient (S_11) graph, when outer radius $\mathrm{R}=8.89 \mathrm{~mm}$ and Inner radius $\mathrm{r}=$ $6.26 \mathrm{~mm}$.

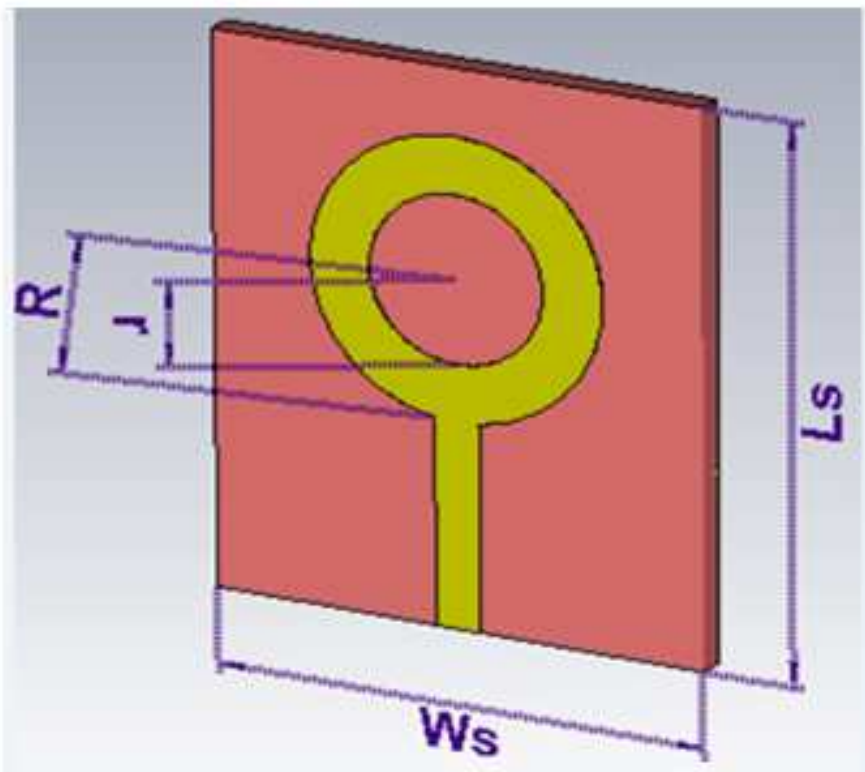

(a)

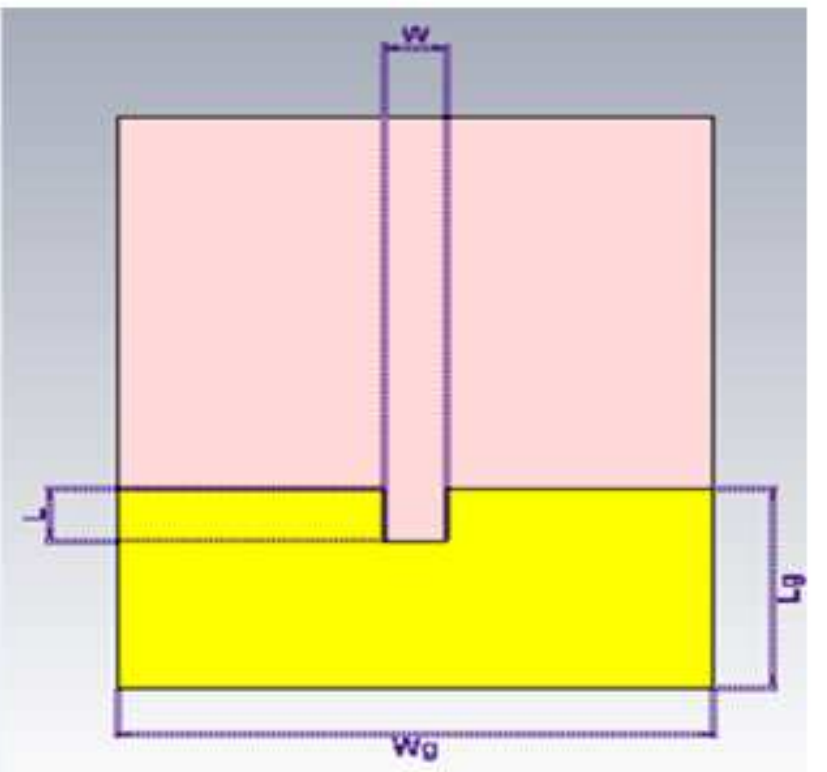

(b)

Figure 2 


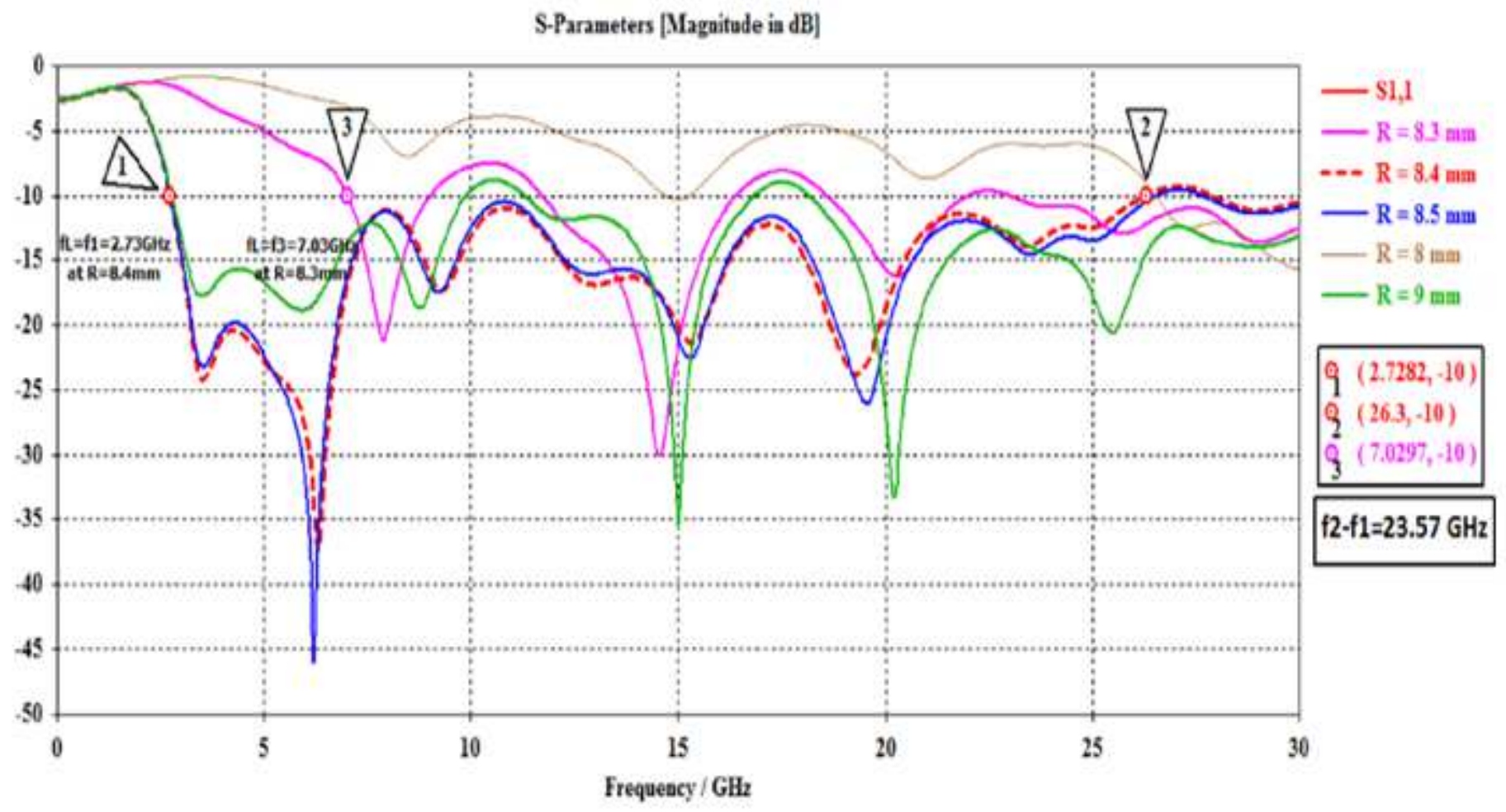

\section{Figure 3}

Frequency vs. reflection coefficient (S_11) graph for different patch outer radius(R)

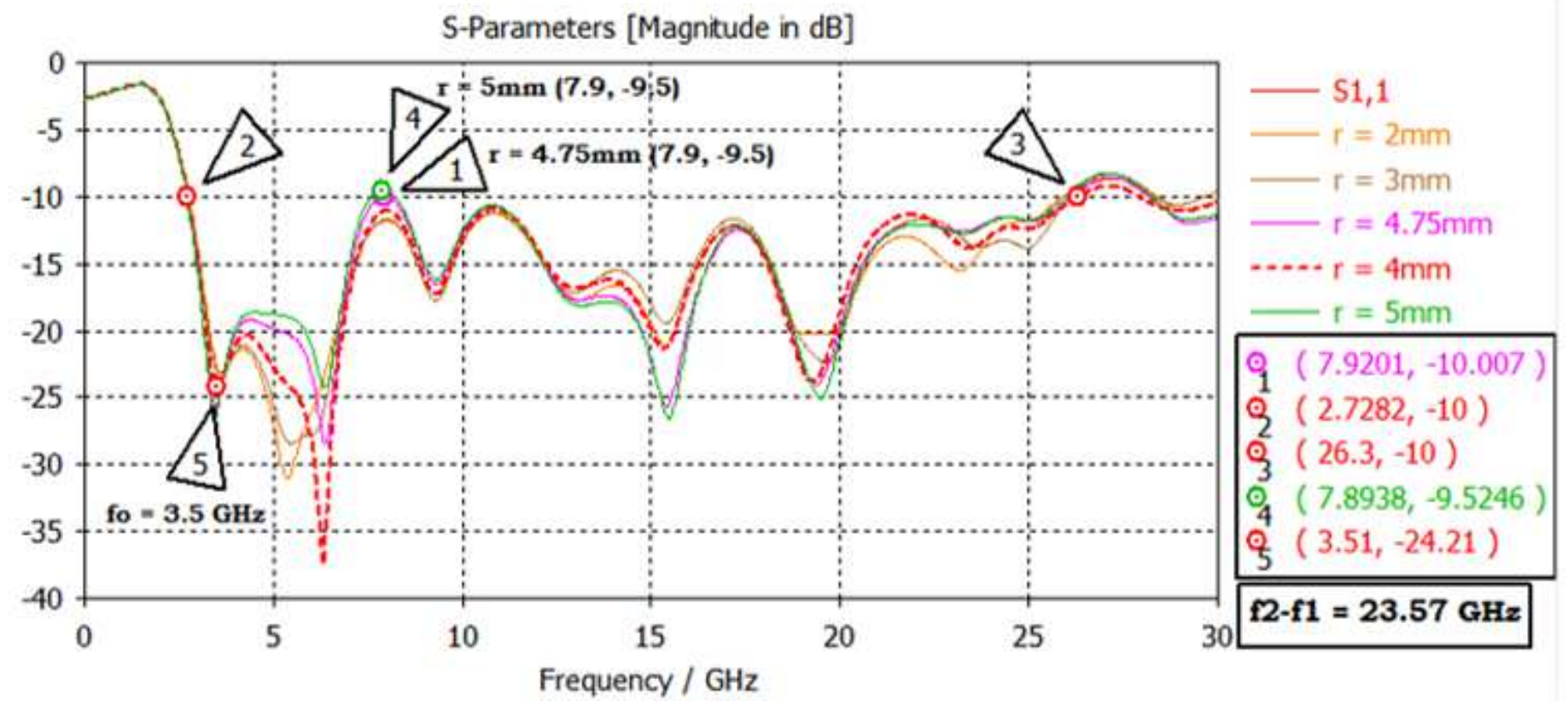

\section{Figure 4}

Frequency vs. reflection coefficient graph for different patch inner Radius (r). 


\section{S-Parameters [Magnitude in dB]}

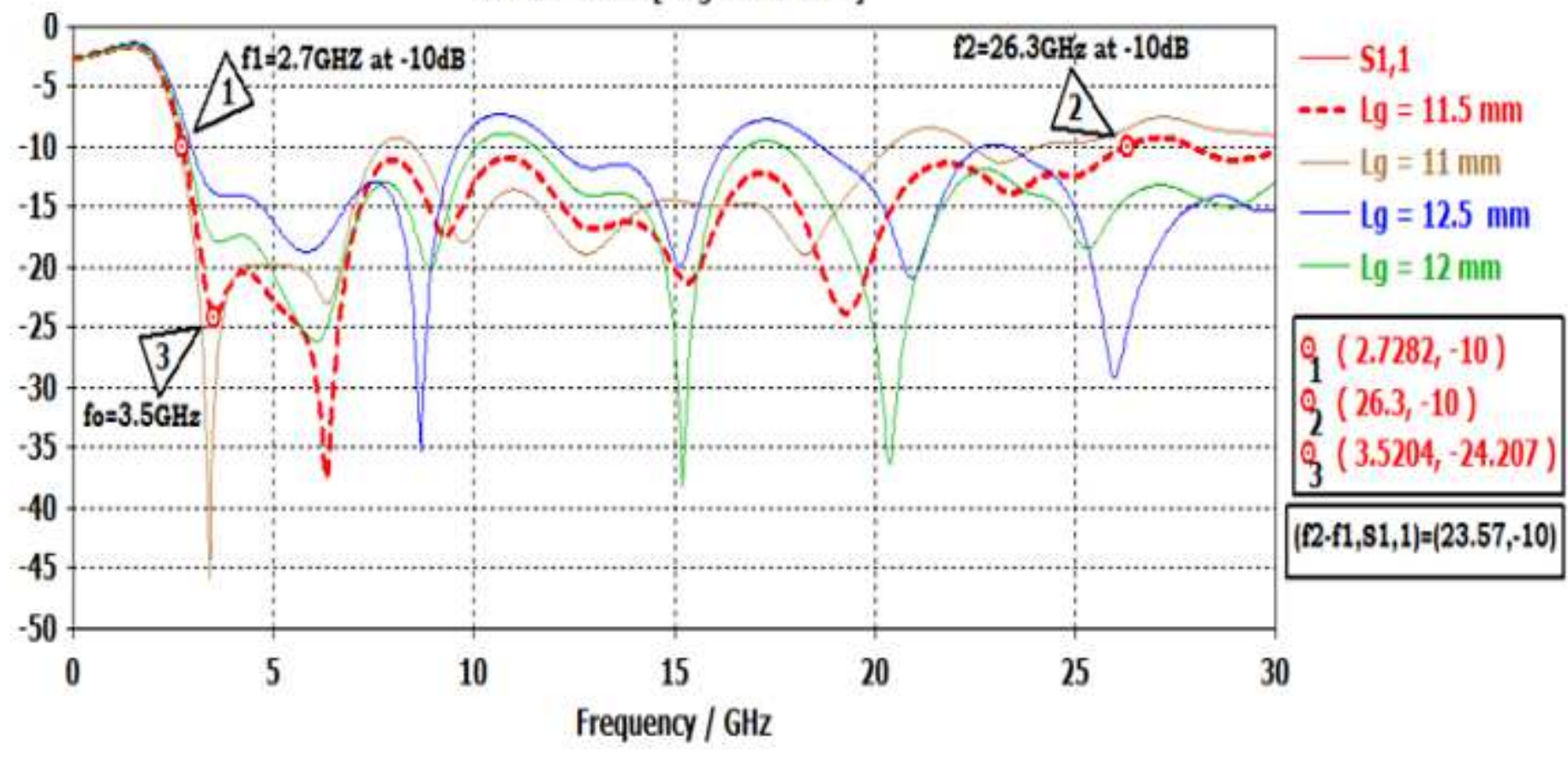

\section{Figure 5}

Frequency vs. reflection coefficient graph for different ground plane length $(\mathrm{Lg})$

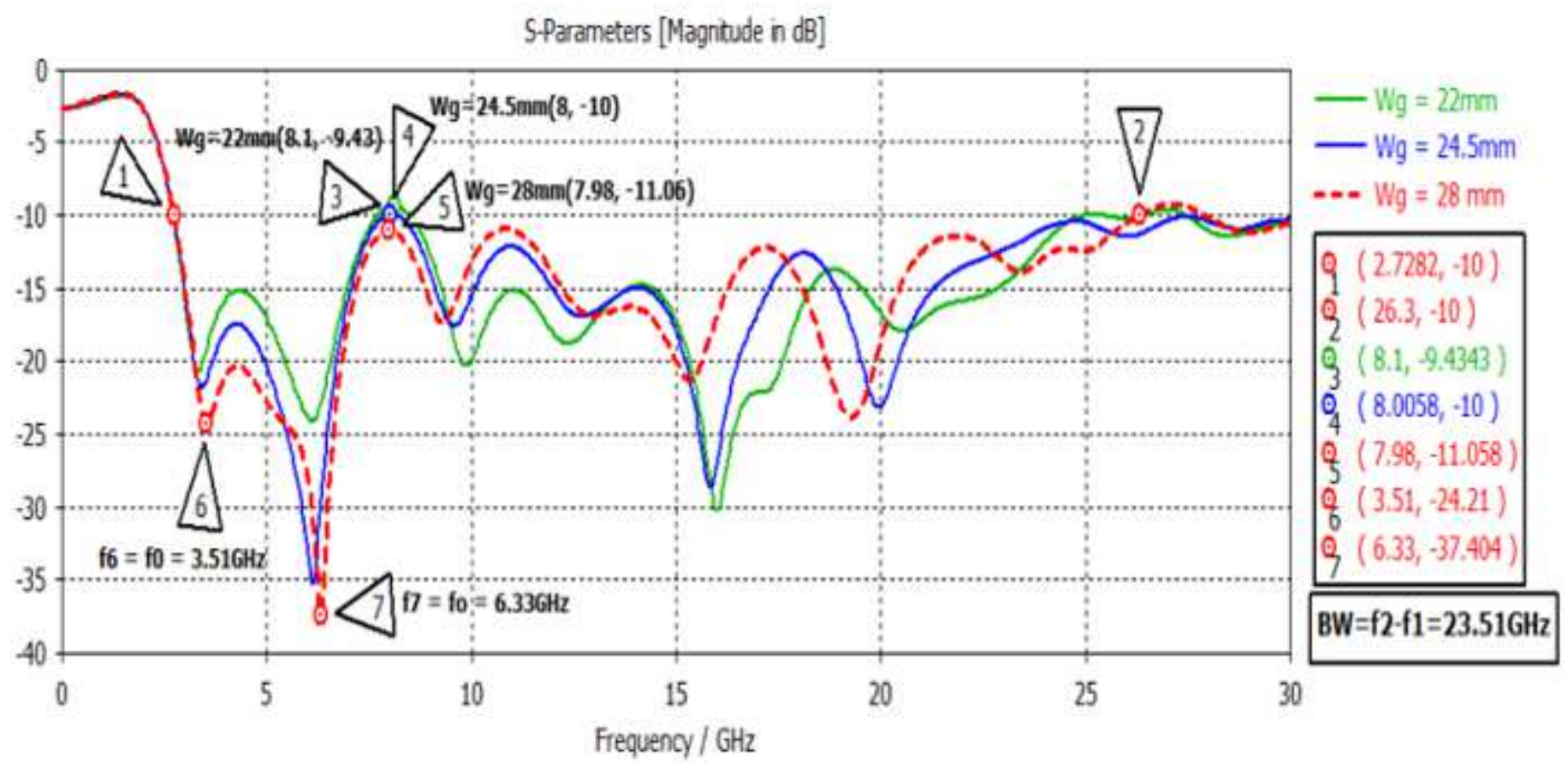

Figure 6

Frequency vs. reflection coefficient graph for different values of ground plan width $(\mathrm{Wg})$. 


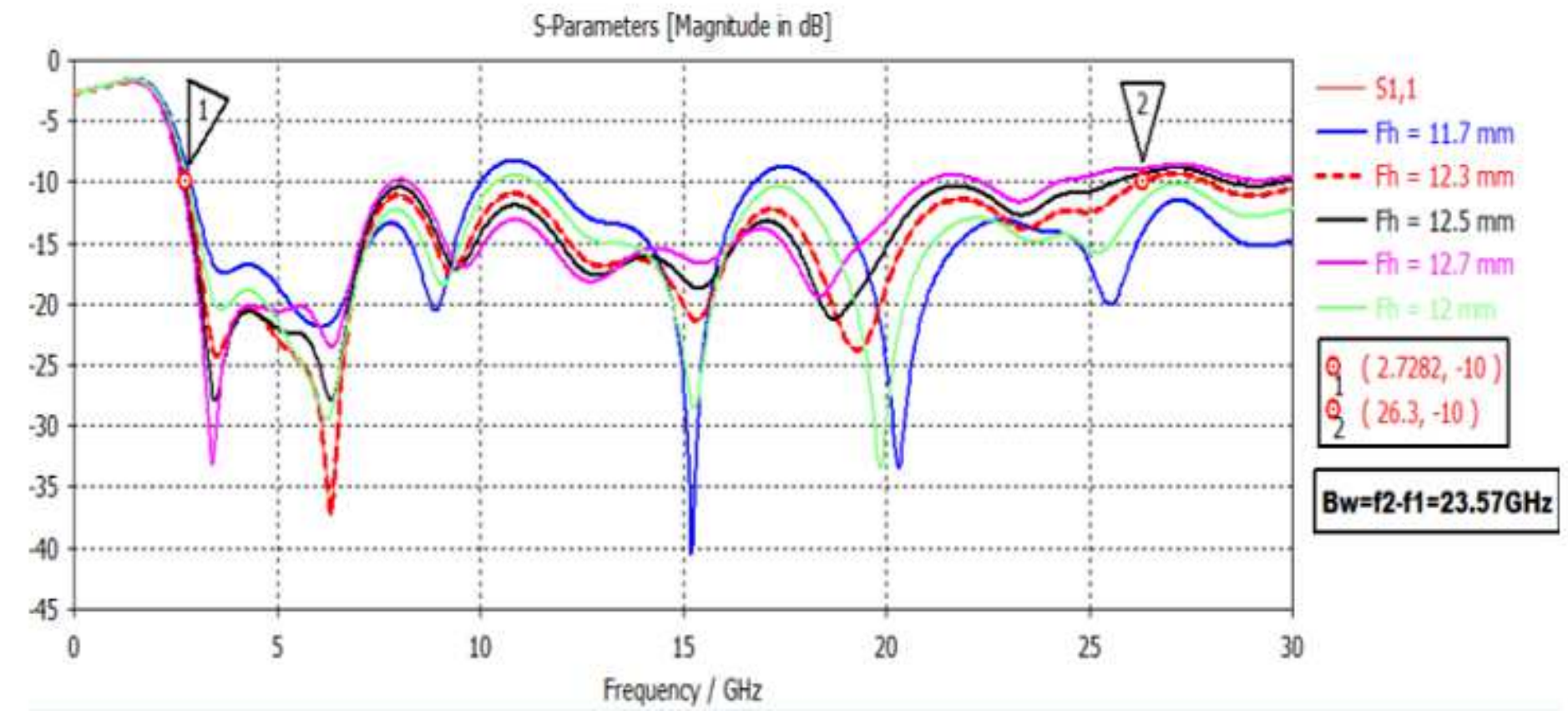

Figure 7

Frequency vs. reflection coefficient graph for different values of feed height (Fh)

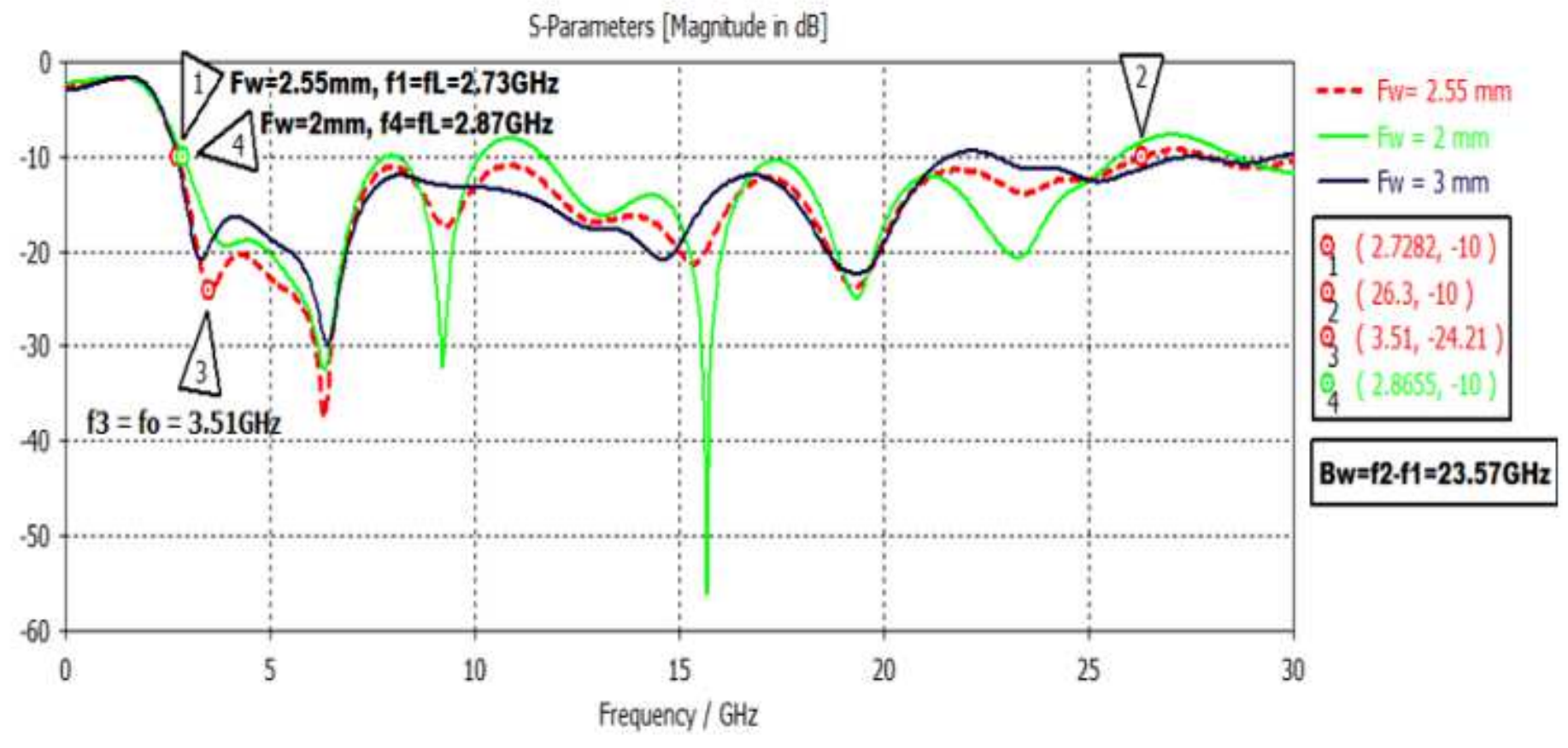

Figure 8

Frequency vs. reflection coefficient graph for different values of feed width(Fw). 
S-Parameters [Magnitude in dB]

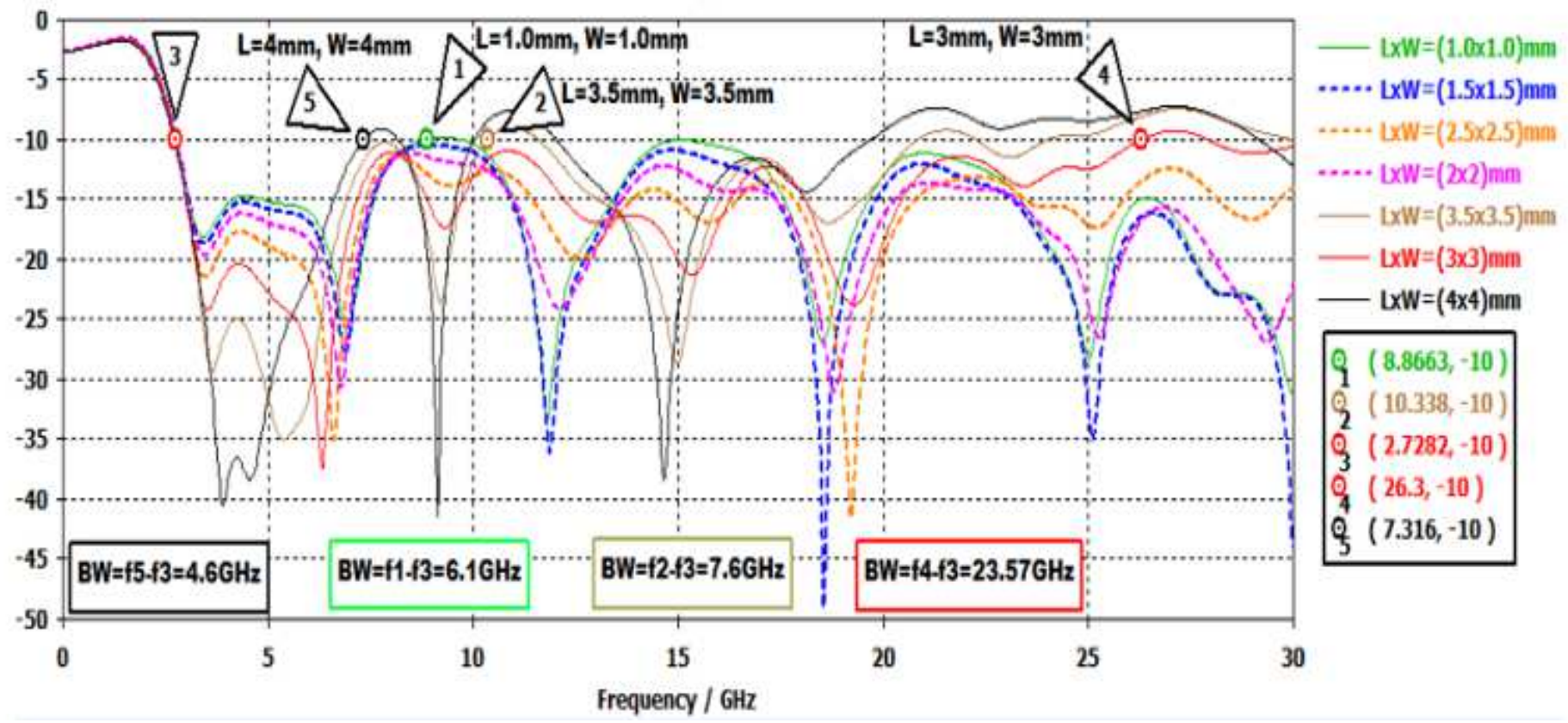

Figure 9

Frequency vs. reflection coefficient graph for different dimension of square shape ground plain SParameters [Magntude in dB]

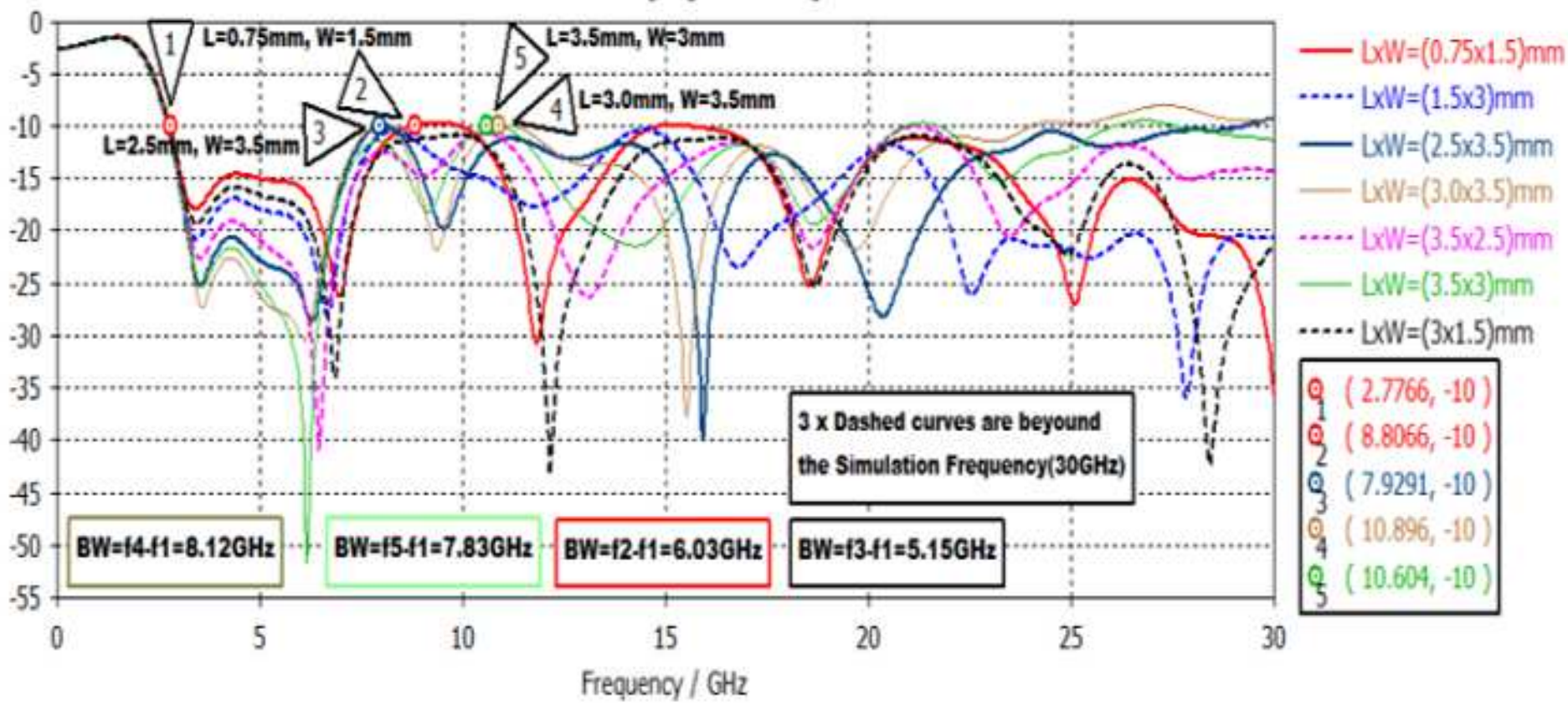

Figure 10

Frequency vs. reflection coefficient graph for different dimension of rectangle before optimization 


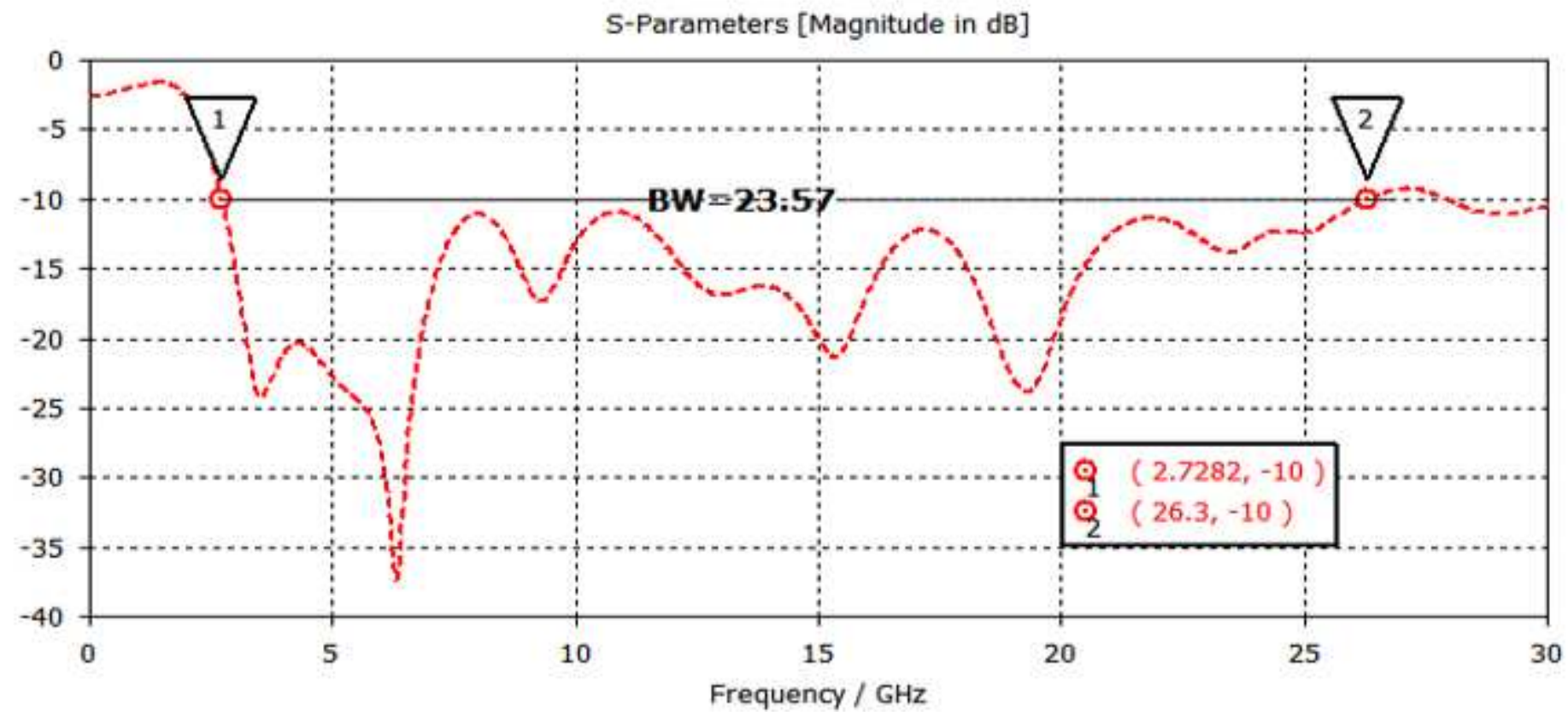

Figure 11

Simulated result for non optimized truncated ground plane, S11 parameter magnitude in $\mathrm{dB}$

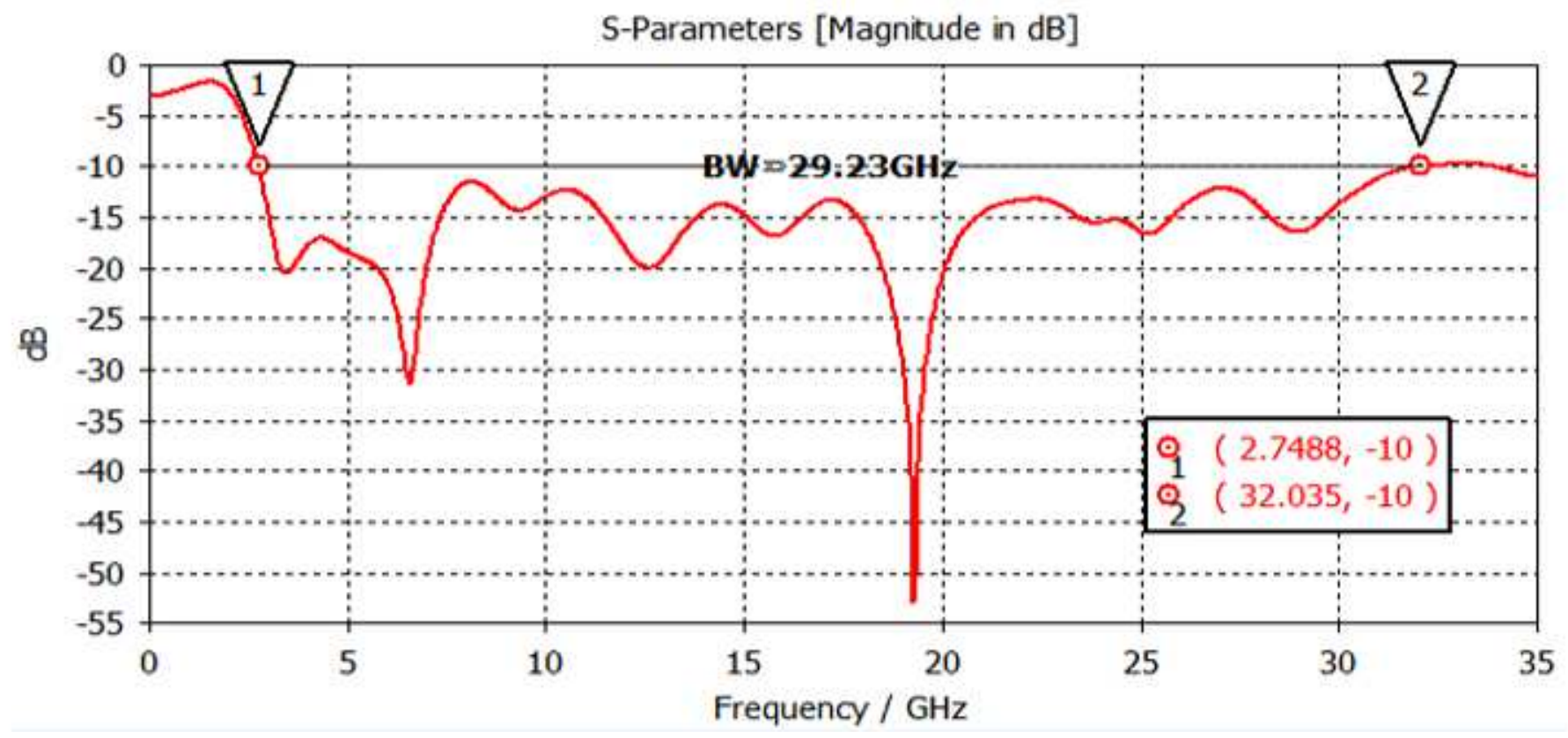

Figure 12

Simulated result for optimized truncated round plane, S11 parameter magnitude in $\mathrm{dB}$ 


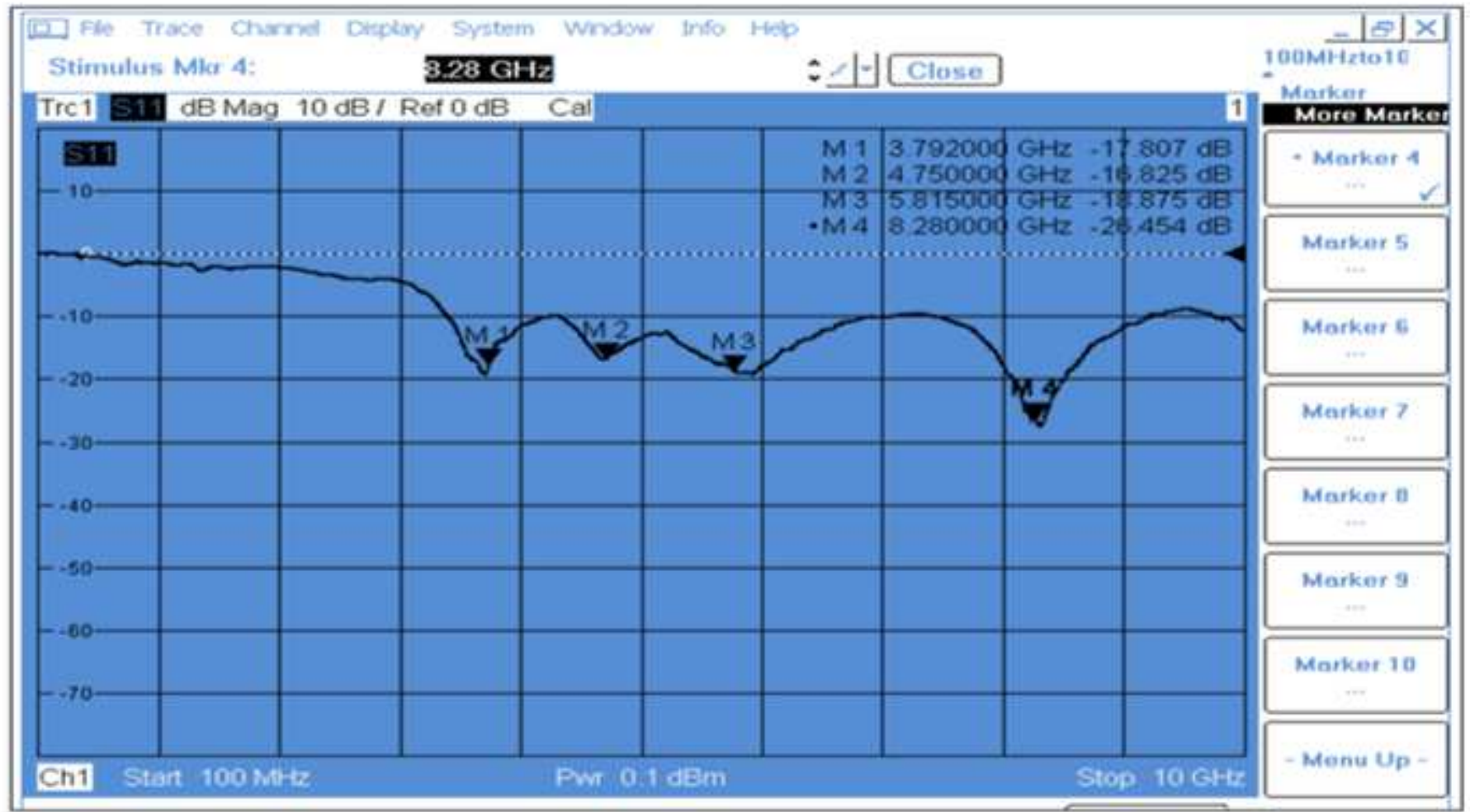

Figure 13

Measured result from $400 \mathrm{MHz}$ to $10 \mathrm{GHz}, \mathrm{S} 11$ parameter magnitude in $\mathrm{dB}$ 


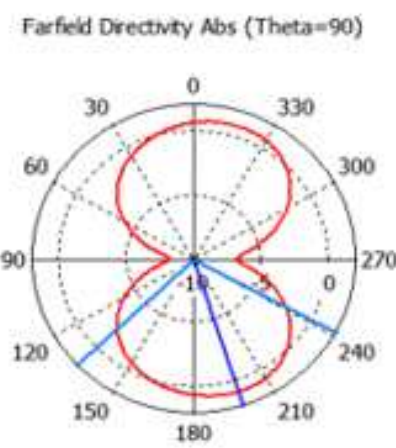

Phi / Degree vs. disi

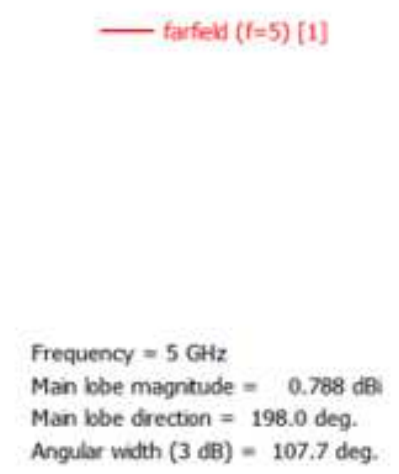

(a)
Farfeld Drectivy Abs (Theta-90)

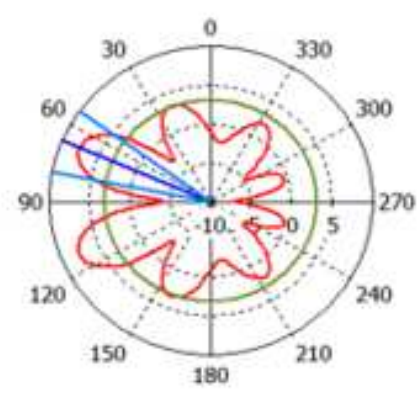

Phi / Degree vs, dB
Frequency $=15 \mathrm{GHz}$ Man lobe magntude $=7.51 \mathrm{dD}$ Man lobe drection $=67.0$ deg. Anpular with $(3 \mathrm{~dB})=24.6 \mathrm{deg}$. Side lobe level $=-4.3 \mathrm{~dB}$

(b)

Farfield Drectivty Abs (Theta $=90$ )

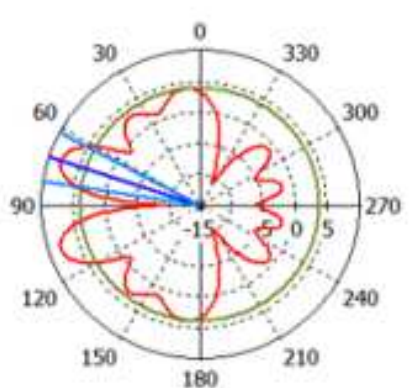

Phi / Degree vs, d8i
- forfedd $(f=20)[1]$

Frequency $=20 \mathrm{GHz}$

Man lobe magntude $=7.8 \mathrm{~d} 8$ Man lobe drection $=72.0 \mathrm{deg}$. Angular width $(3 \mathrm{~dB})=19.4 \mathrm{deg}$ Side bbe level $=-3.9 \mathrm{~dB}$

(c)

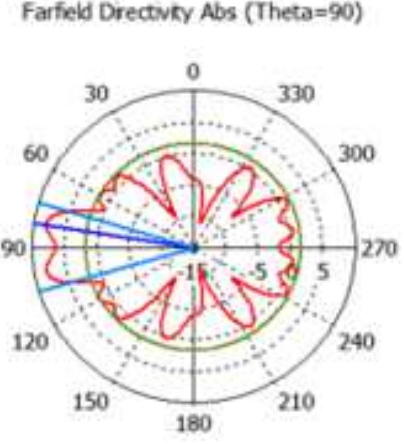

Phi / Degree vs. dBi
- farfied $(f-30)[1]$

Frequency $=30 \mathrm{GHz}$

Man lobe magrtude $=7.87 \mathrm{~dB}$

Man lobe drection $=81.0$ deg.

Angular width $(3 \mathrm{~dB})=33.4 \mathrm{deg}$.

Side bbe level $=-6.1 \mathrm{~dB}$

(d)

\section{Figure 14}

Directivity of optimized Antenna at (a) $5 \mathrm{GHz}$, (b) $15 \mathrm{GHz}$, (c) $20 \mathrm{GHz}$ and (d) $30 \mathrm{GHz}$

\section{Voltage Standing Wave Ratio (VSWR)}

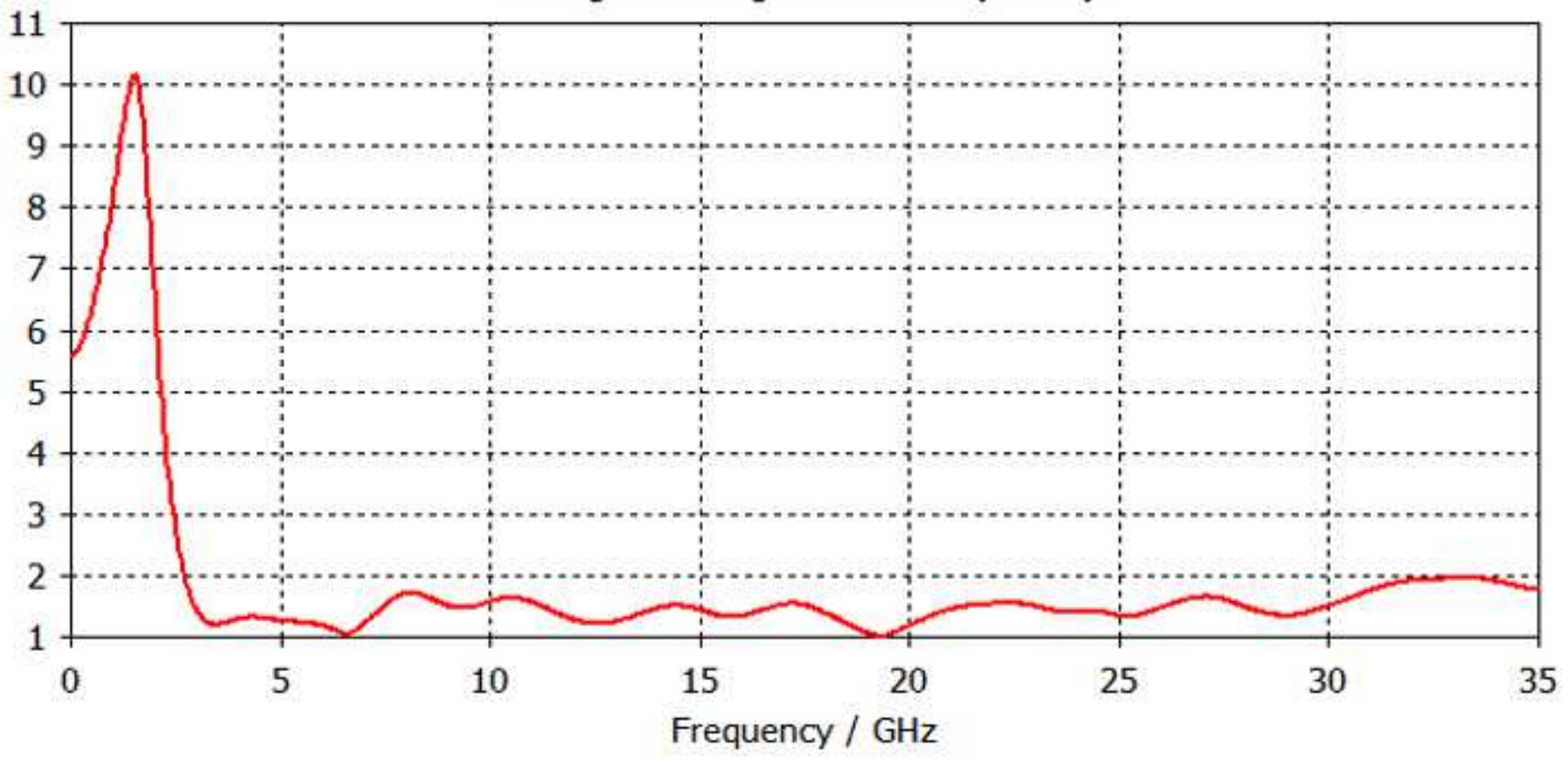


Figure 15

Voltage Standing Wave Ratio graph for proposed optimized Antenna

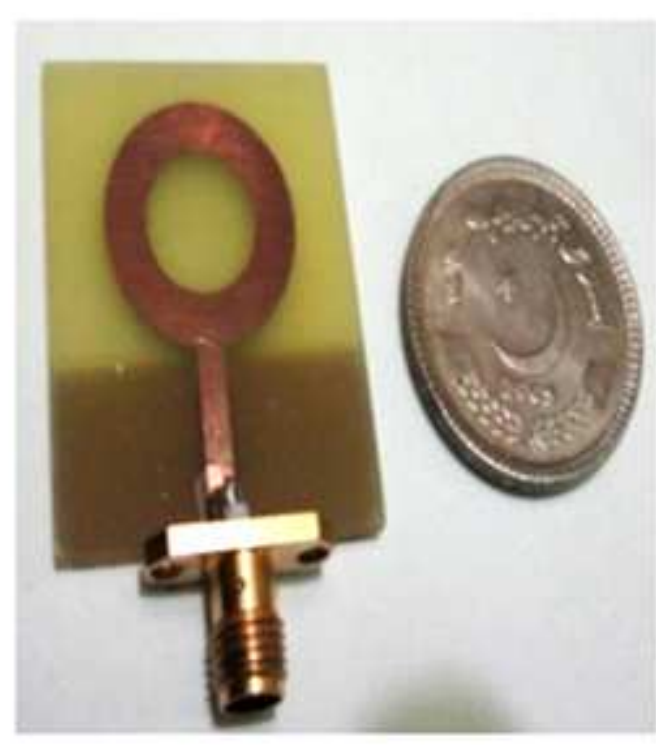

(a)

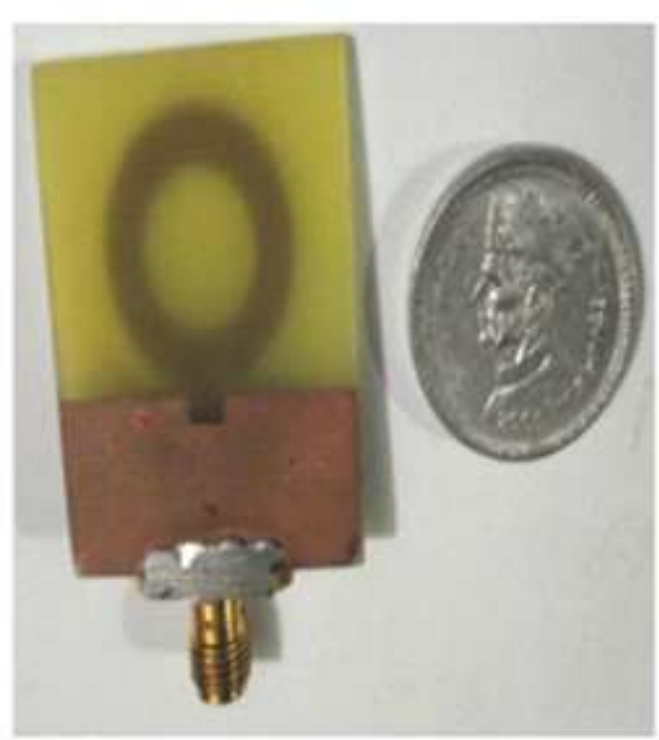

(b)

Figure 16

(a) Front side (b) Back side of fabricated antenna 